\title{
2019 AATS/ACC/ASE/SCAI/STS expert consensus systems of care document: A proposal to optimize care for patients with valvular heart disease
}

\author{
A joint report of the American Association for Thoracic Surgery, American College of Cardiology, American \\ Society of Echocardiography, Society for Cardiovascular Angiography and Interventions, and Society of \\ Thoracic Surgeons
}

\section{Writing Committee:}

\author{
Rick A. Nishimura, MD, MACC (Co-Chair), ${ }^{a}$ Patrick T. O'Gara, MD, MACC (Co-Chair), ${ }^{a}$ \\ Joseph E. Bavaria, MD, FACC, ${ }^{\text {b }}$ Ralph G. Brindis, MD, MPH, MACC, FSCAI, \\ John D. Carroll, MD, FACC, MSCAI, ${ }^{a}$ Clifford J. Kavinsky, MD, PhD, FACC, MSCAI, \\ Brian R. Lindman, MD, MSc, FACC, Jane A. Linderbaum, RN, MS, APRN, CNP, AACC, \\ Stephen H. Little, MD, FACC, FASE, ${ }^{\mathrm{d}}$ Michael J. Mack, MD, FACC, \\ Laura Mauri, MD, MSc, FACC, ${ }^{\text {a }}$ William R. Miranda, MD, ${ }^{2}$ \\ David M. Shahian, MD, FACC, FACS, ${ }^{\mathrm{b}}$ and Thoralf M. Sundt III, MD, FACC
}

\section{TABLE OF CONTENTS}

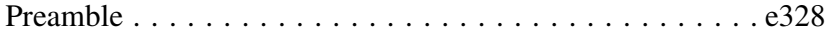

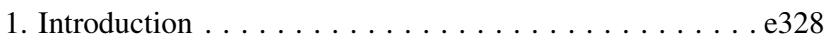

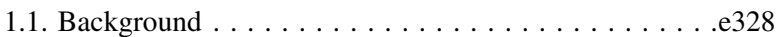

1.2. Statement of the Problem. . . . . . . . . . . e 329

1.3. Purpose of the Document. . . . . . . . . . . . . . e329

1.4. Elements of the Model . . . . . . . . . . . . . . e330

Figure 1. Relationships Among Primary Care Clinicians, General Cardiologists, and Valve Centers... . e330

2. Methods. . . . . . . . . . . . . . . . . . . . e331

3. Historical Perspective From Other Programs . . . . . . e e331

Table 1. Comprehensive/Advanced Care Centers in Other Areas of Medicine......... . e332

4. Proposed Structure for an Integrated Model of Care for Patients With VHD . . . . . . . . . . . . . . . . e332

4.1. Underlying Principles . . . . . . . . . . . . . e 332

4.2. Role of the Primary Care Clinician . . . . . . . . . e333

4.3. Comprehensive (Level I) and Primary (Level II)

Valve Centers . . . . . . . . . . . . . . . . . e333

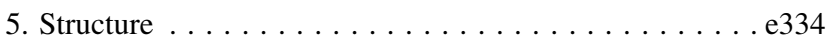

5.1. Structural Requirements of All Advanced Valve Centerse 334

5.2. Structural Components of Advanced Valve Centers. . e334

\footnotetext{
${ }^{a}$ American College of Cardiology representative; ${ }^{b}$ Society of Thoracic Surgeons representative; ${ }^{\mathrm{c}}$ Society for Cardiovascular Angiography and Interventions representative; ${ }^{\mathrm{d}}$ American Society of Echocardiography representative; and ${ }^{\mathrm{e}}$ American Association for Thoracic Surgery representative.

This document was approved by the American Association for Thoracic Surgery (AATS) Council, American College of Cardiology (ACC) Clinical Policy Approval Committee, American Society for Echocardiography (ASE) Board of Directors, the Society for Cardiovascular Angiography and Interventions (SCAI) Board of Directors, and the Society of Thoracic Surgeons (STS) Board of Trustees in October 2018

The American Association for Thoracic Surgery requests that this document be cited as follows: Nishimura RA, O'Gara PT, Bavaria JE, Brindis RG, Carroll JD, Kavinsky CJ, Lindman BR, Linderbaum JA, Little SH, Mack MJ, Mauri L, Miranda WR, Shahian DM, Sundt TM III. 2019 AATS/ACC/ASE/SCAI/ STS expert consensus systems of care document: a proposal to optimize care for patients with valvular heart disease: a joint report of the American Association for Thoracic Surgery, American College of Cardiology, American Society of Echocardiography, Society for Cardiovascular Angiography and Interventions, and Society of Thoracic Surgeons. J Thorac Cardiovasc Surg. 2019;157:e327-54.
}

5.2.1. Transcatheter Treatments . . . . . . . . . . . e334

5.2.2. Cardiac Surgical Procedures. . . . . . . . . e 334

Table 2. Structure of Valve Centers . . . . . . . . e 335

Table 3. Additional Possible Catheter-Based Therapies at Level I Centers . . . . . . . . . . e336

5.2.3. Imaging. . . . . . . . . . . . e 336

5.2.4. Personnel, Institutional Facilities, and Infrastructure . . . . . . . . . . . . e 337

Table 4. The Multidisciplinary Team-Minimum Requirements . . . . . . . . . . e337

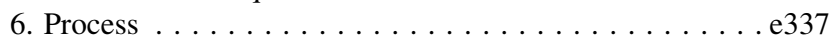

6.1. Process Requirements for Advanced Heart Valve

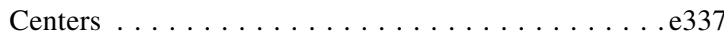

Table 5. Processes for Valve Centers . . . . . . . . e338

6.2. Process Components for Advanced Heart Valve

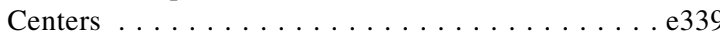

6.2.1. Function of the MDT . . . . . . . . e339

6.2.2. Registry Participation . . . . . . . . . . e339

6.2.3. Research . . . . . . . . . . . . . . . . e 340

6.2.4. Education . . . . . . . . . . . . . . e 340

6.2.5. Training. . . . . . . . . . . . . e340

7. Performance Metrics . . . . . . . . . . . . . . . e340

This article has been copublished in Catheterization and Cardiovascular Interventions, the Journal of the American Society of Echocardiography, the Journal of Thoracic and Cardiovascular Surgery, and the Annals of Thoracic Surgery.

Copies: This document is available on the World Wide Web sites of the American Association for Thoracic Surgery (www.aats.org), American College of Cardiology (www.acc.org), American Society of Echocardiography (www.ase.org), Society for Cardiovascular Angiography and Interventions (www.scai.org), and Society of Thoracic Surgeons (www.sts.org). For copies of this document, please contact Elsevier Inc. Reprint Department via fax (212-633-3820) or e-mail (reprints@ elsevier.com).

Permissions: Multiple copies, modification, alteration, enhancement, and/or distribution of this document are not permitted without the express permission of the American Association for Thoracic Surgery. Requests may be completed online via the Elsevier site (https://www.elsevier.com/about/policies/copyright/permissions).

J Thorac Cardiovasc Surg 2019;157:e327-54

$0022-5223 / \$ 36.00$

(C) 2018 by the American Association for Thoracic Surgery, the American College of Cardiology Foundation, the American Society of Echocardiography, the Society for Cardiovascular Angiography and Interventions, and the Society of Thoracic Surgeons https://doi.org/10.1016/j.jtcvs.2019.03.004 
See Commentary on page 2214.

7.1. Assessment of Quality of Care and Development of Performance Metrics for VHD Centers . . . . . . . . e341 Figure 2. Categorization of Sites Based on TAVR Volume and Risk-Adjusted Mortality . . . e e342 7.1.1. TAVR . . . . . . . . . . . . . . . e 343 7.1.2. Surgical Mitral Valve Repair . . . . . . . . . e343 Table 6. TAVR Program Performance Minimum Quality Benchmarks ............ e 344 Table 7. TAVR Program Performance Criteria. . . e344 Table 8. Mitral Valve Repair Performance Criteria-For Primary Degenerative MR . . e345

7.2. Public Reporting. . . . . . . . . . . . . . . . . . .e345

8. Obstacles and Challenges to a VHD System of Care. . e345

9. Summary and Next Steps . . . . . . . . . . . . . e346

Presidents and Staff. . . . . . . . . . . . . . . . . e346

References . . . . . . . . . . . . . . . . . . . . . e347

Appendix $1 \ldots \ldots \ldots \ldots \ldots \ldots \ldots$. . . . . . . . . . . . . . . . . . . . . . . . . . . . .

Abbreviations . . . . . . . . . . . . . . . . . . . e349

Appendix $2 \ldots \ldots \ldots \ldots \ldots \ldots \ldots \ldots \ldots$. . . . . . . . . . . 350

Author Relationships With Industry and Other Entities

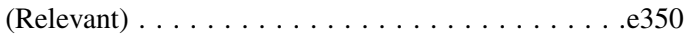

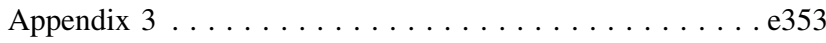

Peer Reviewer Relevant RWI . . . . . . . . . . . . .e353

\section{PREAMBLE}

This statement was commissioned as a Multisociety Expert Consensus Systems of Care Document by the American Association for Thoracic Surgery (AATS), American College of Cardiology (ACC), American Society of Echocardiography (ASE), Society for Cardiovascular Angiography and Interventions (SCAI), and Society of Thoracic Surgeons (STS). Expert Consensus Systems of Care Documents are intended to summarize the position of these partnering organizations on the availability, delivery, organization, and quality of cardiovascular care, with the intention of establishing appropriate benchmarks. These Systems of Care Documents are overseen by the ACC Task Force on Health Policy Statements and Systems of Care.

With the rapid evolution and dissemination of transcatheter technologies, as well as advances in surgical repair and valve replacement techniques, there is an imperative for the cardiovascular community to establish the provider, institutional, and systems-based standards for delivery of high-quality valvular heart disease (VHD) care. The AATS, ACC, ASE, SCAI, and STS have, therefore, joined together to provide expert consensus and, wherever feasible, evidence-based recommendations for systems of care related to VHD, in the spirit of ensuring access to quality outcomes. The writing group anticipates that future updates to this consensus statement will be necessary as newer imaging and treatment technologies become available and more data are generated regarding patient outcomes, cost, and cost-effectiveness.
Dharam J. Kumbhani, MD, SM, FACC Chair, ACC Task Force on Health Policy Statements and Systems of Care

\section{INTRODUCTION \\ 1.1. Background}

In the past decade, the evaluation and management of patients with VHD has changed dramatically. Advances in noninvasive imaging have enabled reliable, reproducible, and objective measurements of valve disease severity, along with an appreciation of any associated hemodynamic and structural consequences. There is enhanced understanding of the natural history of VHD based upon longitudinal studies of large numbers of patients that have correlated outcomes with noninvasive measurements as well as with data obtained during exercise testing. Advances in surgical techniques, especially those associated with valve repair; improved operative results; and perioperative management strategies have contributed substantially to better patient outcomes. Transcatheter aortic valve replacement (TAVR) has revolutionized the treatment of patients with symptomatic, severe aortic stenosis (AS) and now provides a less-invasive treatment option for many eligible patients. Transcatheter repair of mitral regurgitation (MR) with an edge-to-edge clip device occupies a specific treatment niche currently, and more options for this valve lesion are anticipated in the near future. Transcatheter mitral valve replacement (TMVR) is the subject of intense investigation, and tricuspid valve interventions in high-surgical-risk patients are being developed. Collectively, these advances have led to an increasing number of treatment options, lower thresholds for and earlier timing of intervention, and the provision of less-invasive therapies to an older, sicker, and more frail population. ${ }^{1,2}$ As the number and complexity of VHD treatment options have expanded, expert clinical judgment from an experienced multidisciplinary team (MDT) has assumed increasing importance.

The number of patients with significant VHD who could benefit from appropriate intervention increases as a function of age. The elderly are the fastest growing segment of the United States population. Estimates of the prevalence of moderate or severe aortic or mitral disease in United States patients over the age of 75 years approach $4 \%$ and $10 \%$, respectively. ${ }^{3}$ The prevalence of moderate or severe VHD in a large-scale community screening program of patients over age 65 years in the United Kingdom exceeded $11 \%$, with a projected doubling before $2050 .{ }^{4}$ The number of patients who will be eligible for TAVR is estimated to increase 4-fold over the next 5 years. ${ }^{5,6}$ Accordingly, implementation of optimal treatment strategies for patients with VHD will affect a sizable portion of the population. Access to appropriate care is critical, but as the complexity and cost of diagnosis and treatment continues to increase, it will not be feasible for all institutions to provide the full complement of resources and clinical experts necessary to 
care for the full spectrum of patients with VHD, while also ensuring the highest-quality outcomes.

\subsection{Statement of the Problem}

Providing optimal care to patients with VHD is an increasingly complex process, starting with early recognition and diagnosis at the primary care/general cardiology level and including appropriate timing of referral for further evaluation and management, MDT assessment, shared decision-making, and long-term follow-up. In the past, intervention for VHD was often delayed until the onset of severe symptoms. It is now recognized that the longstanding effects of VHD can lead to irreversible changes in left ventricular (LV) function, repeated hospitalizations, patient morbidity (eg, atrial fibrillation, heart failure, endocarditis), reduced quality of life (QOL), and premature mortality, which can often be prevented by earlier treatment. However, prior studies estimated that nearly $30 \%$ to $50 \%$ of patients with severe VHD who met guideline criteria for intervention were not appropriately recognized or referred, ${ }^{8-11}$ even in highly resourced environments. ${ }^{7,12}$

There are an increasing number of treatment options available to patients with VHD; yet, not all patients are aware of or have access to the full spectrum of interventions. For most patients with severe primary MR, for example, it is wellrecognized that mitral valve repair is superior to mitral valve replacement. ${ }^{13-15}$ However, repair rates for primary MR vary significantly among individual surgeons and across institutions. ${ }^{16-20}$ Although repair rates for primary MR have increased, ${ }^{21-24}$ there remains concern that many patients with anatomy amenable to repair instead undergo valve replacement, with adverse downstream consequences related to $\mathrm{LV}$ dysfunction and the presence of valve prostheses. Similarly, some patients with symptomatic severe AS, as well as their providers, may not be aware that they would be eligible for TAVR due to the lack of a system of care that might enable them to access comprehensive MDT consultation with all treatment options being considered. Alternatively, TAVR may be inappropriately recommended when surgical aortic valve replacement (SAVR), sometimes in combination with aortic or coronary bypass surgery, would be a better option. Patients and referring providers may be unaware of specific physician competencies or experience, center volumes, structure, processes, or outcomes. Other less-invasive procedures for selected valverelated problems may be performed only at certain institutions, such as percutaneous closure of paravalvular leaks, alternativeaccess TAVR, and valve-in-valve procedures for degenerated surgical bioprostheses. Ideally, personnel and resource restrictions at one institution should not negate the opportunity for referral to another with a wider array of services and a more established MDT.

\subsection{Purpose of the Document}

The intent of this document is to propose a system of care for patients with VHD, the primary goal of which would be to optimize outcomes for all patients and ultimately improve the care of VHD at all centers. This approach is intended to increase the identification of patients with VHD and emphasize best practices as captured in the 2014 AHA/ACC Guideline for the Management of Patients with Valvular Heart Disease ${ }^{2}$ and the 2017 AHA/ACC Focused Update of the 2014 AHA/ACC Guideline for the Management of Patients With Valvular Heart Disease. ${ }^{25}$ It is also intended to promote the efficient utilization of resources, facilitate communication and continuity of care, and emphasize the need for transparency in reporting of and accountability for outcomes relative to national benchmarks. The standards proposed for the optimal structure and function of valve centers, as well as key processes of care, mirror those in a companion 2018 AATS/ACC/SCAI/STS Expert Consensus Systems of Care Document: Operator and Institutional Recommendations and Requirements for Transcatheter Aortic Valve Replacement document. ${ }^{26}$ An interconnected system of providers and institutions may help strike the right balance between access and quality outcomes. The case for centers with the ability to offer more comprehensive care is logical, but it is critically important that patients and referring clinicians be made aware of the quality of care delivered in all centers. A major priority in optimizing VHD patient care is to identify and support centers with excellent outcomes and improve outcomes at centers where opportunities exist, not simply to promote those centers with good reputations or large procedural volumes.

A systems approach to the management of patients with VHD could help promote care among centers in a manner analogous to those adopted for the management of other medical and surgical disorders such as stroke and trauma, ${ }^{27,28}$ thereby improving outcomes. On the basis of experience in other disciplines, this proposal includes the adoption of 2 tiers of valve centers, namely comprehensive (Level I) and primary (Level II) valve centers, the attributes of which should be defined by objective criteria (Figure 1). The intent is not to limit the number of centers per se but rather to set performance and quality goals for a valve center to meet benchmarks to be considered either comprehensive or primary in a manner that would be more objective than simple selfdesignation. The guiding principle in such a model would be to optimize the care of the individual patient by ensuring access to the right care in the right place at the right time, while promoting shared decision making (SDM) and respecting individual values and preferences. This principle can be applied to the clinician who must identify the presence of potentially important VHD, to the primary center providing local care for several conditions, and to the comprehensive center offering the full spectrum of services. Any such system of care should allow patients to be cared for at the appropriate level, promote seamless transitions 


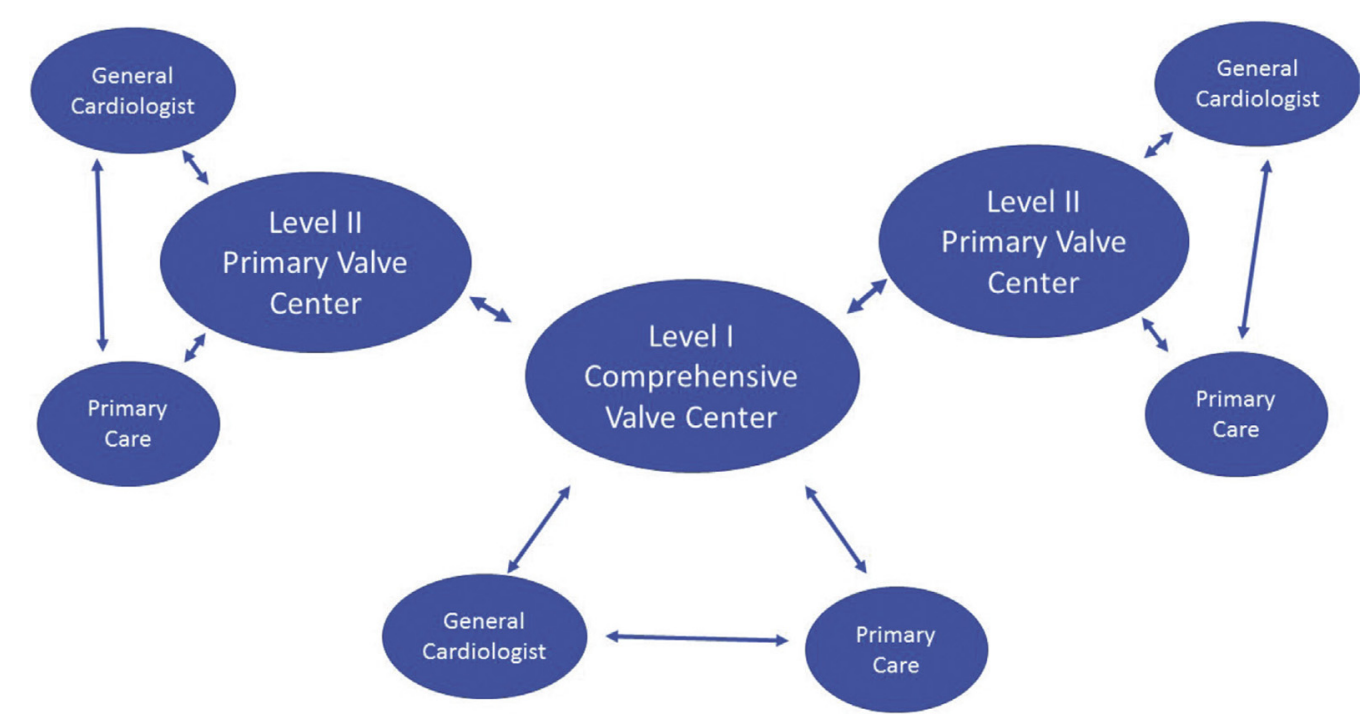

FIGURE 1. Relationships among primary care clinicians, general cardiologists, and valve centers.

between different levels of care when necessary, and place a premium on communication and shared learning. Patients with VHD should be informed of their treatment options, including those not routinely offered locally or through their health plan, and be given the opportunity to pursue alternatives according to their own expectations and preferences. The geographical, cultural, and financial barriers to establishing a system of care are recognized; yet the rational dissemination of complex care models founded on the principle of highest-quality outcomes that matter to patients remains an important goal.

\subsection{Elements of the Model}

Knowledge of VHD pathophysiology and natural history, the essentials of patient assessment, and the range of available treatment options is expected across all levels of providers. Current knowledge and performance gaps around recognition and treatment relate to the decline in physical examination skills and a lack of appreciation of the improvement in outcomes seen in patients previously deemed too ill or frail for intervention. It is the responsibility of professional societies and individual valve centers to provide education, support, and guidance for the appropriate management of VHD patients and to minimize any such gaps. Many sections of the 2014 AHA/ACC Guidelines for the Management of Patients with Valvular Heart Disease and its 2017 AHA/ACC Focused Update of the 2014 AHA/ACC Guideline for the Management of Patients With Valvular Heart Disease are a resource for the primary care physician/general cardiologist. In addition, there are several ongoing ACC efforts to provide concise and relevant tools for VHD patient diagnosis and treatment, including the Managing Aortic Stenosis and Emerging Mitral Regurgitation Clinical Care initiatives.
The proposed system of care would typically begin at the local level, with community providers and primary (Level II) valve centers communicating openly and collaborating with a comprehensive (Level I) center (Figure 1). Ideally, patient movement within such a system would be predicated on the desire to match the complexity of disease with the appropriate resources while placing a premium on maintaining relationships between patients and their longstanding healthcare providers.

For example, there are patients with primary MR who might benefit from referral to the highest level of VHD care. Patients with severe primary MR may have complex valve pathology that makes durable surgical repair technically challenging, such as anterior leaflet or bileaflet disease, Barlow's disease, or extensive annular or subvalvular calcification. The decision to operate on an asymptomatic patient with severe primary MR and preserved LV and systolic function is complex and hinges critically on the likelihood of a successful, durable repair in the hands of an experienced mitral surgeon working in collaboration with intraoperative echocardiographic imaging experts. ${ }^{1,2,17}$ In addition, the successful management of atrial fibrillation at the time of mitral valve surgery may require comprehensive approaches to ablation that are not widely practiced.

The management of patients with AS should also be considered in the context of the appropriate level of care within an organized system. Transfemoral TAVR has become available in over 580 sites in the United States, but there remain nearly as many centers that only offer SAVR. Hence, access to TAVR technology, when considered preferable to operative intervention, may require directed referral to a partner institution or center. Patients who are not candidates for transfemoral TAVR may benefit 
from alternate access techniques, which might not be available at all TAVR sites. It is well-documented that the results of SAVR vary across sites. ${ }^{29,30}$ The optimal performance of aortic valve surgery in some patients may require additional operative techniques. Patient-prosthetic mismatch is not uncommon in small patients who may receive small valves, resulting in compromised long-term outcomes. The expertise to perform more-complicated operations, including aortic valve repair, valve-sparing root reconstruction, root enlargement, composite valve graft replacement, ascending aortic/hemi-arch replacement, and myectomy for subvalvular obstruction, is not widespread, underscoring the need for a system of care that facilitates triaging such patients to the appropriate level.

It is important that centers designated as having VHD expertise not only perform certain procedures, but also have MDTs capable of assessing and managing patients according to evidence-based guidelines while emphasizing SDM. The MDT and the valve center are responsible for maintaining performance standards and improving quality. Communication between centers and among referring providers is essential for fulfilling these responsibilities. Public reporting is a critical part of the continuous quality improvement process, and risk-adjusted results should be made available to referring physicians, patients, and families.

\section{METHODS}

The ACC convened the Evolving Valve Management Strategies Roundtable in December 2016. The Roundtable was a multidisciplinary effort to facilitate the identification of gaps and challenges in the care of patients with VHD and a component of the ACC's Succeed in Managing Heart Disease Initiative. Multiple medical and surgical subspecialty stakeholders and advanced practice clinicians participated in the Roundtable. Also participating were representatives of government (ie, pre- and postmarket divisions of the Food and Drug Administration, Centers for Medicare and Medicaid Services, and National Institutes of Health), industry, integrated health systems, and patient groups, as well as systems of care experts from other specialties (stroke). The discussions identified support for the goals of providing patients with VHD access to an integrated system of care delivery, ensuring rigorous quality assessment and improvement, and focusing on patientcentered outcomes. As a result of these discussions, a writing committee was formed to create a proposal outlining the structure, processes, and essential components of an integrated system of care for VHD patients.

The writing committee was composed of representatives from the AATS, ACC, ASE, SCAI, and STS. Existing organized and tiered systems of care for the treatment of several other acute disorders (trauma, stroke, S-T segment elevation myocardial infarction [STEMI]) and non-acute (bariatric surgery, cancer) were reviewed by the committee. A leading member of the Brain Attack Coalition had previously presented the elements of that system to the Roundtable. Where appropriate, the writing committee referred to multisocietal recommendations for operator and institutional procedural volumes, infrastructure, personnel, and reporting requirements. This document was built upon the 2014 AHA/ACC Guidelines for the Management of Patients with Valvular Heart Disease and its 2017 Focused Update, as well as other ACC documents, including the 2017 ACC Expert Consensus Decision Pathway for Transcatheter Aortic Valve Replacement, the 2017 ACC Expert Consensus Decision Pathway for Mitral Regurgitation, the ACC/AATS/AHA/ASE/EACTS/ HVS/SCA/SCAI/SCCT/SCMR/STS 2017 Appropriate Use Criteria for the Treatment of Patients With Severe Aortic Stenosis, and the 2018 AATS/ACC/SCAI/STS Expert Consensus Systems of Care Document: Operator and Institutional Recommendations and Requirements for Transcatheter Aortic Valve Replacement. ${ }^{31-35}$

The format was based on the Donabedian model, which incorporates: (1) structure; (2) process; and (3) outcomes. The financial and political implications of developing a system of care for VHD patients were discussed, taking into account the tension between: (1) patient access to highly impactful yet expensive technology; and (2) the need to ensure highest-quality outcomes while minimizing cost, risks, and any potential unintended consequences.

The work of the writing committee was supported exclusively by the ACC without commercial support. Writing committee members volunteered their time to this effort. Conference calls of the writing committee were confidential and attended only by committee members and society staff. A formal peer review process was completed consistent with ACC policy and included expert reviewers nominated by the ACC (see Appendix 3). A public comment period was also provided to obtain additional perspective. Following reconciliation of all comments, this document was approved for publication by the ACC Clinical Policy Approval Committee, the AATS Council, the ASE Board of Directors, the SCAI Board of Directors, and the STS Executive Committee of the Board of Directors.

\section{HISTORICAL PERSPECTIVE FROM OTHER PROGRAMS}

Organized and tiered systems of care in other areas of medicine have been developed and embedded in the complex and large U.S. healthcare system. Often a key question is: what should constitute the designation of a center within a system as specialized and comprehensive? Examples of requirements for such a designation are available in multiple areas of medicine, both for acute problems (stroke, trauma, and myocardial infarction) and selected chronic disorders (bariatric surgery for obesity, adult congenital disease, pulmonary hypertension) (Table 1). Each system is different in terms of its intent and outcome; however, each is an organized and tiered system of care. These systems also differ with respect to accreditation and designation within a tiered structure. While this review focuses on specialized centers of care, there is no intent to diminish the important role played by clinicians at the primary care level who are responsible for initial recognition and triage of patients with VHD.

The first U.S. Cancer Centers were established in 1960 by the National Institutes of Health, with the objective of addressing research and training. ${ }^{36}$ Currently, there are 70 specialized cancer centers across 35 states. Motivated by the wide variability in the quality of care and the disparate outcomes of patients with traumatic injuries, the American College of Surgeons published a statement in $1976^{37}$ describing 3 tiers of trauma centers with graded infrastructure, personnel requirements, and site visits by an accreditation body. They proposed a coordinated network of centers, in which seriously injured patients could be transferred to a regional center with the highest available density of expert trauma services. The development of this network of specialized trauma centers has been associated with improved patient outcomes in both urban and rural areas. ${ }^{38,39}$ 
TABLE 1. Comprehensive/advanced care centers in other areas of medicine

\begin{tabular}{|c|c|c|c|c|c|}
\hline & Cancer & Trauma & Stroke & Bariatric surgery & STEMI \\
\hline Year initiated & 1960 & 1976 & 2001 & 2005 & $2006 / 2007$ \\
\hline $\begin{array}{l}\text { Sponsoring } \\
\text { organization }\end{array}$ & $\begin{array}{l}\text { National Institutes } \\
\text { of Health }\end{array}$ & $\begin{array}{c}\text { American College } \\
\text { of Surgeons }\end{array}$ & Brain Attack Coalition & $\begin{array}{l}\text { American Society of } \\
\text { Bariatric Surgery } \\
\text { American College of } \\
\text { Surgeons }\end{array}$ & $\begin{array}{l}\text { American College of } \\
\text { Cardiology } \\
\text { (D2B Alliance) } \\
\text { American Heart Association } \\
\text { (Mission: Lifeline) }\end{array}$ \\
\hline Levels of care & $\begin{array}{l}\text { Basic Laboratory } \\
\text { Cancer Center } \\
\text { Cancer Centers } \\
\text { Comprehensive } \\
\text { Cancer Center }\end{array}$ & $\begin{array}{l}\text { Level I } \\
\text { Level II } \\
\text { Level III } \\
\text { Level IV }\end{array}$ & $\begin{array}{l}\text { Acute Stroke-Ready hospital } \\
\text { Primary Stroke Center } \\
\text { Comprehensive Stroke } \\
\text { Center }\end{array}$ & $\begin{array}{l}\text { Bariatric Surgery Center } \\
\text { of Excellence }\end{array}$ & $\begin{array}{l}\text { STEMI-referral hospital } \\
\text { (non-PCI capable) } \\
\text { STEMI-receiving hospital } \\
\text { (PCI-capable) }\end{array}$ \\
\hline
\end{tabular}

D2B, Door to Balloon; PCI, percutaneous coronary intervention; STEMI, ST-segment elevation myocardial infarction.

Inspired by the successful outcomes achieved by the implementation of trauma centers, the Brain Attack Coalition proposed and implemented the establishment of multidisciplinary acute stroke centers. The Coalition has defined the components of Primary and Comprehensive Stroke Centers and of Acute Stroke-Ready Hospitals. ${ }^{27,40,41}$ This initiative established the foundation for accreditation of stroke centers. Based on the Brain Attack Coalition recommendations, different organizations (the Joint Commission, Det Norske Veritas Germanischer Lloyd, and Health Care Facilities Accreditation Program) have developed certification programs to recognize hospitals possessing the required infrastructure and personnel to best treat patients with stroke.

Variability in surgical outcomes prompted the American Society of Bariatric Surgery and the American College of Surgeons to designate centers of excellence to standardize care and ensure high-quality management of morbidly obese patients undergoing weight reduction surgery. ${ }^{42}$ Similar to stroke centers, bariatric surgery centers participate in an accreditation process that was introduced to ensure that quality metrics are met.

For patients with cardiovascular disease, the development of local networks to streamline and improve the treatment and outcomes of patients with acute STEMI spread widely in response to the recognition that reperfusion times were often inappropriately prolonged. $^{43}$ To ensure the provision of optimal care, networks for patients with chronic cardiovascular diseases have also been established. For example, in the United Kingdom's National Health Service, congenital heart disease care has been redirected; 3 tiers of care, ranging from local to specialist surgical centers, have been organized to provide different levels of care according to patient need. ${ }^{44}$ In the United States, adult congenital heart disease centers (https://www.achaheart. org/provider-support/accreditation-program) as well as pulmonary hypertension centers (https://phassociation.org/ phcarecenters/medical-professionals/center-criteria/) have been formally designated after meeting rigorous requirements upon external review. The European Society of Cardiology has issued a position paper on heart valve centers that mandates evaluation and care for all patients with VHD by dedicated physicians working in specialized environments. ${ }^{45}$

The aforementioned initiatives have had several effects, including: (1) increased access to high-quality care due to awareness of a system that designates centers as having met criteria (including quality metrics) for accreditation; (2) reduced mortality for trauma patients ${ }^{46}$; (3) decreased mortality and improved rates of timely tissue plasminogen activator (tPA) administration/ mechanical reperfusion in appropriate patients with ischemic stroke ${ }^{35,47}$; (4) improved safety and reduced costs for patients undergoing bariatric surgery ${ }^{48,49}$; (5) improved guideline-directed therapy and outcomes in patients with STEMI $^{50}$; and (6) recognition-based external accreditation using objective criteria and periodic reviews.

\section{PROPOSED STRUCTURE FOR AN INTEGRATED MODEL OF CARE FOR PATIENTS WITH VHD}

\subsection{Underlying Principles}

The development of an integrated model of care for patients with VHD is based on the concept of a graduated system in which the first tier has the critical function of recognition and consideration of referral. Subsequently, the patient is matched on the basis of disease complexity with the required center expertise, experience, and availability of resources. The following principles are emphasized:

- The primary goal is to improve the care of all patients with VHD.

- The first step is recognition and subsequent diagnosis of VHD, usually by a primary care physician, advanced practice provider, or general cardiologist. 
- The second step often involves referral to a local general cardiologist who can further refine the diagnosis, initiate medical therapy as indicated, and identify those who can be managed for the time being without further intervention or who may need more specialized care such as surgery or transcatheter valve repair or replacement.

- Access to specialized care requires establishment of well-defined referral lines to centers having graduated levels of expertise and resources (Figure 1). Increasing disease complexity often requires higher-order, comprehensive care at a Level I center, whereas less complex disease can be managed at a Level II center.

- A Multidisciplinary Team (MDT) and an emphasis on patient shared decision-making are essential to the operations of both Level I and II valve centers.

- Full institutional support is required for provision of appropriate imaging and procedural resources, equity among the individual stakeholders of the MDT, care pathways that span the continuum, registry participation, and results reporting.

- Transparency, public reporting, mandatory participation in national registries, ongoing analysis of processes and outcomes, and a commitment to research are essential.

- Bidirectional communication and ongoing education of members of the MDT and the community of referring providers/centers are required to improve the quality of care in all settings.

- Processes of care should emphasize informed consent (information provided in various formats and languages), SDM, patient experiences, and individual choices.

\subsection{Role of the Primary Care Clinician}

By combining patient evaluations (history, physical examination, electrocardiogram, laboratory studies) with appropriate utilization of echocardiography, ${ }^{51}$ primary care and practice-level clinicians play a vital gatekeeper role within a system of care for VHD. Approximately $70 \%$ of all echocardiograms performed in Medicare beneficiaries are ordered by a noncardiologist provider. $^{52}$ When significant VHD is suspected or confirmed, most patients should be referred to a local or regional cardiovascular specialist for further evaluation and management. The role of the primary care provider in recognizing VHD symptoms, initiating diagnostic testing, referring for specialized care, and establishing patient expectations cannot be overemphasized. It is also recognized that referral for specialized care may not be appropriate for certain patients. Therefore, defined pathways for patient referral that incorporate bidirectional communication between primary and subspecialty providers should be created. As the breadth of diagnostic approaches to VHD continues to expand (eg, cardiac magnetic resonance, computed tomography [CT], 3-dimensional [3D] echocardiography, strain imaging), and as surgical and catheter-based treatment options continue to evolve, educational programs directed at the primary care provider assume increasing importance. ${ }^{11}$

Although electronic medical record systems have improved the communication of personal health information between primary and subspecialty care providers, the systematic integration of imaging data has generally not kept pace. A principal component of a well-designed system of care for VHD would be secure access to digital data of any diagnostic imaging procedure performed. This access would accelerate appropriate patient referrals, limit the need for repeat diagnostic procedures, and provide a platform to facilitate feedback on image quality. The roles of brief, simple, handheld echocardiographic scans during physical examinations (supported by machine learning algorithms to identify the potential need for a more detailed study) and alert notifications (eg, suggesting referral to a specialist) on noninvasive imaging reports should also be considered.

\subsection{Comprehensive (Level I) and Primary (Level II) Valve Centers}

The proposed integrated model for a VHD system of care is shown in Figure 1. A Comprehensive (Level I) Valve Center should have the resources and capabilities to evaluate and perform all commercially approved interventional and surgical procedures. A Level I center should also have advanced imaging modalities (eg, 3D echocardiography, cardiac magnetic resonance) that may not be available at a Level II center. A Primary (Level II) Valve Center should have, at a minimum, the expertise and resources to perform transfemoral TAVR and surgical procedures such as isolated SAVR. The ability to perform a durable mitral valve repair in patients with primary MR due to posterior leaflet pathology is desirable but not mandatory for a center to be defined as a Primary (Level II) Valve Center. If complex valve procedures are performed at the Primary (Level II) Valve Center, the same performance standards and expected outcomes as at a Comprehensive (Level I) Valve Center should be achieved. Patients can enter the system from multiple pathways. Each system of care should develop its own criteria for communication, feedback, and transfer. Level I and II Valve Centers should utilize the results of testing performed at referring practices and centers. Facilitation of long-term care of patients at the local level is of critical importance.

The following sections of the document provide recommendations for Level I and II Valve Center designations in relation to: (1) structure; (2) process; and (3) outcomes. "Structure" consists of institutional facilities and infrastructure, personnel, and types of procedures. "Process" comprises the requirements and function of the MDT, including its participation in registries, 
research, and education. Finally, "outcomes" consists of a combination of the number of procedures performed and procedural success, morbidity, mortality, and QOL after intervention.

\section{STRUCTURE}

\subsection{Structural Requirements of All Advanced Valve Centers}

Table 2 lists the recommended minimum procedural, institutional, and infrastructural requirements for the 2 levels of valve centers. Additional procedures may be performed at each center but are not required. Table 3 lists additional procedures that are not included in Table 2 but may be of benefit to selected subsets of patients with VHD. The major distinction between centers resides chiefly in the broader spectrum of services and higher density of expert personnel available at the Level I (Comprehensive) Center.

\subsection{Structural Components of Advanced Valve Centers}

\subsubsection{Transcatheter treatments}

Interventional cardiologists and cardiac surgeons at Comprehensive (Level I) and Primary (Level II) Valve Centers should have the expertise in catheter-based techniques necessary for evaluating and managing VHD. These include invasive hemodynamic assessment of VHD, coronary angiography and intervention, and peripheral vascular angiography and intervention. Additional expertise for the interventionalist at a Comprehensive (Level I) Valve Center includes atrial septal puncture and percutaneous closure of atrial septal defects. Proceduralists at all centers must be able to prevent, recognize, and treat complications and be skilled in coronary and peripheral vascular rescue and retrieval techniques (eg, use of snares and forceps) for embolized devices; pericardiocentesis; and vascular access management, including use of covered endovascular stents. Collectively, these skills provide necessary support for catheter-based valve therapies. Beyond technical and procedural skills, the valve interventionalist must also develop expertise related to patient selection, including knowledge of the natural history of VHD, optimal timing for interventions, appropriate judgment about anticipated risks and benefits of an intervention, and the ability to determine the appropriate therapy for a specific pathology. These physicians should have the knowledge and skills to participate in SDM with patients and families.

The interventional procedural requirements for Comprehensive (Level I) and Primary (Level II) Valve Centers are outlined in Table 2. Proceduralists at both Comprehensive (Level I) and Primary (Level II) Valve Centers should be able to perform TAVR using a transfemoral approach and percutaneous balloon aortic valve dilation.
Comprehensive (Level I) Valve Centers should also have the personnel and facilities to perform alternative-access (nontransfemoral) site TAVR, including transthoracic and extrathoracic approaches. The additional expertise and procedural volumes at a Comprehensive (Level I) Valve Center would be expected to reduce the risk of complications related to nonfemoral access. Valve-invalve procedures for degenerated aortic and mitral bioprosthetic valves should be available at a Comprehensive (Level I) Valve Center. Selected operators at a Comprehensive (Level I) Valve Center should be proficient in performing transcatheter mitral valve repair using the edge-to-edge technique, as well as percutaneous mitral balloon commissurotomy. Percutaneous closure of paravalvular leaks should be offered by the Comprehensive (Level I) Valve Center. Other procedures might be performed by the Comprehensive (Level I) Valve Center, such as left atrial appendage occlusion, complex septal defect closures, and alcohol septal ablation. Emerging therapies, including transcatheter mitral valve replacement, next-generation transcatheter mitral valve repairs, and tricuspid valve procedures, are not required but will likely be performed at a Comprehensive (Level I) Valve Center participating in ongoing investigational device studies. If a Primary (Level II) Center offers additional procedures that might traditionally be provided at a Comprehensive (Level I) Center, the same quality and outcome reporting requirements should be maintained.

\subsubsection{Cardiac surgical procedures}

Both Comprehensive (Level I) and Primary (Level II) Valve Centers are expected to perform isolated SAVR with or without coronary artery bypass grafting. A Comprehensive (Level I) Valve Center should have the personnel and resources for performing more complex surgical procedures to treat other subsets of patients with VHD. The benefit of performing these procedures at Comprehensive (Level I) Centers extends beyond merely technical expertise and higher volumes. The composition of the MDT, as well as infrastructural and institutional resources, can be leveraged to optimize decision making and clinical care and to strengthen clinical training around complex VHD patients. Advanced surgical expertise is required to perform complex aortic root procedures, including composite valve root replacement and valve-sparing root repair. A Comprehensive (Level I) Center should also house the surgical skill and resources to treat patients with complicated infective endocarditis. In patients with AS who have concomitant septal hypertrophy, a myectomy at the time of SAVR is sometimes necessary to prevent dynamic outflow tract obstruction. Root enlargement to allow for larger-sized prosthetic valves should be available for patients with small annulus sizes. Successful repair of mitral valve disease, including durable repair not only for primary MR involving the posterior 
TABLE 2. Structure of valve centers

Comprehensive (Level I) valve center

Primary (Level II) valve center

\section{Interventional procedures}

TAVR-transfemoral

Percutaneous aortic valve balloon dilation

TAVR-alternative access, including transthoracic (transaortic, transapical) and extrathoracic (eg, subclavian, carotid, caval) approaches

Valve-in-valve procedures

Transcatheter edge-to-edge mitral valve repair

Paravalvular leak closure

Percutaneous mitral balloon commissurotomy

\section{Surgical procedures}

SAVR

SAVR

Valve-sparing aortic root procedures

Aortic root procedures for aneurysmal disease

Concomitant septal myectomy with AVR

Root enlargement with AVR

Mitral repair for primary MR

Mitral valve replacement

Mitral repair for posterior leaflet primary MR $\dagger$

Mitral valve replacement

Multivalve operations

Reoperative valve surgery

Isolated or concomitant tricuspid valve repair or replacement

\section{Imaging personnel}

Echocardiographer with expertise in valve disease and transcatheter and surgical interventions

Expertise in CT with application to valve assessment and procedural planning

Interventional echocardiographer to provide imaging guidance for transcatheter and intraoperative procedures ${ }^{53}$

Expertise in cardiac MRI with application to assessment of VHD

Criteria for imaging personnel

A formalized role/position for a "valve echocardiographer" who performs both the pre- and postprocedural assessment of valve disease

A formalized role/position for the expert in CT who oversees the preprocedural assessment of patients with valve disease

A formalized role/position for an interventional echocardiographer

\section{Institutional facilities and infrastructure}

\section{MDT (Table 3)}

A formalized role/position for a dedicated valve coordinator who organizes care across the continuum and system of care

Cardiac anesthesia support

Palliative care team

Vascular surgery support

Neurology stroke team

Consultative services with other cardiovascular subspecialties (see Section 5.2.4 Personnel, Institutional Facilities, and Infrastructure)
TAVR-transfemoral

Percutaneous aortic valve balloon dilation
Mitral valve replacement surgical interventions planning

Concomitant tricuspid valve repair or replacement with mitral surgery

Echocardiographer with expertise in valve disease and transcatheter and

Expertise in CT with application to valve assessment and procedural

A formalized role/position for a "valve echocardiographer" who performs both the pre- and postprocedural assessment of valve disease

A formalized role/position for the expert in CT who oversees the preprocedural assessment of patients with valve disease

\section{MDT (Table 3)}

A formalized role/position for a dedicated valve coordinator who organizes care across the continuum and system of care

Cardiac anesthesia support

Palliative care team

Vascular surgery support

Neurology stroke team 
TABLE 2. Continued

\begin{tabular}{|c|c|}
\hline Comprehensive (Level I) valve center & Primary (Level II) valve center \\
\hline \multicolumn{2}{|l|}{$\begin{array}{l}\text { Consultative services with other medical and surgical subspecialties } \\
\text { (see Section 5.2.4 Personnel, Institutional Facilities, and Infrastructure) }\end{array}$} \\
\hline $\begin{array}{l}\text { Echocardiography-3D TEE; comprehensive TTE for assessment of valve } \\
\text { disease }\end{array}$ & Echocardiography-comprehensive TTE for assessment of valve disease \\
\hline Cardiac CT & Cardiac CT \\
\hline $\mathrm{ICU}$ & ICU \\
\hline $\begin{array}{l}\text { Temporary mechanical support (including percutaneous support devices } \\
\text { such as intra-aortic balloon counterpulsation, temporary percutaneous } \\
\text { ventricular assist device or ECMO) }\end{array}$ & $\begin{array}{l}\text { Temporary mechanical support (including percutaneous support devices } \\
\text { such as intra-aortic balloon counterpulsation, temporary percutaneous } \\
\text { ventricular assist device or ECMO) }\end{array}$ \\
\hline \multicolumn{2}{|l|}{$\begin{array}{l}\text { Left/right ventricular assist device capabilities (on-site or at an affiliated } \\
\text { institution) }\end{array}$} \\
\hline $\begin{array}{l}\text { Cardiac catheterization laboratory, hybrid catheterization laboratory, } \\
\text { or hybrid OR laboratory } \S\end{array}$ & Cardiac catheterization laboratory \\
\hline PPM and ICD implantation & PPM and ICD implantation \\
\hline \multicolumn{2}{|l|}{ Criteria for institutional facilities and infrastructure } \\
\hline IAC echocardiography laboratory accreditation & IAC echocardiography laboratory accreditation \\
\hline \multicolumn{2}{|l|}{ 24/7 intensivist coverage for ICU } \\
\hline $\begin{array}{l}A V R \text {, Aortic valve replacement; } C T \text {, computed tomography; } E C M O \text {, extracorporea } \\
\text { Accreditation Commission; } I C U \text {, intensive care unit; } M D T \text {, multidisciplinary tea } \\
P P M \text {, permanent pacemaker; } S A V R \text {, surgical aortic valve replacement; TAVR, transcat } \\
\text { chocardiography; } V H D \text {, valvular heart disease. *A Primary (Level II) Center may pro } \\
\text { s the criteria for competence and outcomes are met. } \dagger \text { If intraoperative imaging and s } \\
\text { with a fixed radiographic imaging system and flat-panel fluoroscopy, offering cathet }\end{array}$ & $\begin{array}{l}\text { brane oxygenation; } I C D \text {, implantable cardioverter defibrillator; } I A C \text {, Intersoci } \\
R \text {, mitral regurgitation; } M R I \text {, magnetic resonance imaging; } O R \text {, operating roo } \\
\text { ortic valve replacement; TEE, transesophageal echocardiography; } T T E \text {, transthora }\end{array}$ \\
\hline
\end{tabular}

leaflet, but also for anterior leaflet prolapse, bileaflet prolapse, and Barlow's disease, should be offered at the Comprehensive (Level I) Valve Center. Repair of posterior leaflet prolapse might also be offered at a Primary (Level II) Valve Center depending on the level of surgical and imaging expertise and experience. Surgical mitral valve replacement should be available at both Level I and II centers. Annuloplasty repair of tricuspid regurgitation is often a straightforward addition to mitral repair in appropriate patients. The evaluation and surgical management (repair or replacement) of severe, secondary MR with regional or global LV systolic dysfunction, however, can be challenging and, for some patients, may be more appropriate at a Level I Center. Multivalve operations (other than simple annuloplasty tricuspid repair added to mitral valve surgery),

TABLE 3. Additional possible catheter-based therapies at Level I centers

\begin{tabular}{l}
\hline Left atrial appendage closure \\
ASD or VSD closure \\
Alcohol septal ablation \\
Mitral valve replacement, mitral valve repair with techniques other than \\
edge-to-edge clip system (currently investigational devices) \\
Tricuspid valve repair \\
Pulmonary balloon valvotomy or valve replacement \\
\hline$A S D$, Atrial septal defect; $V S D$, ventricular septal defect.
\end{tabular}

reoperative valve surgery, operations for prosthetic valve endocarditis, and hybrid transcatheter/surgical procedures are likely better suited for a Comprehensive (Level I) Valve Center.

\subsubsection{Imaging}

Consistent, high-quality imaging and interpretation are critical to evaluation, management, and procedural guidance for patients with VHD. Accurate echocardiographic assessment of the etiology and severity of VHD is often the pivotal first step in management. Valve centers require an echocardiographer with expertise in valve disease, which includes an understanding of pitfalls in assessing valve lesion severity; quantification of lesion severity; evaluation of complex, multivalve disease; determination of anatomic suitability and procedural success for both catheter-based and surgical procedures; and identification of postprocedural complications.

Although echocardiography is the primary imaging modality for assessing VHD, cardiac and vascular CT has become an indispensable tool for appropriate planning of transcatheter interventions. Cardiac magnetic resonance imaging is increasingly used to assess regurgitant lesion severity and ventricular function. High-quality CT image acquisition, post-processing, and $3 \mathrm{D}$ reconstruction are minimum requirements. Accurate measurements of intracardiac and vascular access route dimensions are critical. 
As treatment options rapidly expand for VHD, a new specialty of interventional echocardiography is emerging. ${ }^{53}$ Interventional echocardiographers blend a sophisticated knowledge of echocardiography with clinical expertise and can help guide management decisions at the point of intervention. They have become integral to the high performance of any MDT, especially at Comprehensive (Level I) Centers. The interventional echocardiographer is a critical participant in select valve cases (eg, transcatheter mitral valve repair and repair of paravalvular leaks). Effectiveness in this role requires an individual who has regular involvement in these procedures and thus is familiar with the devices and procedural steps, is competent to provide interventionalists with imaging guidance for transcatheter procedures, understands how echocardiography can help avoid or identify procedural complications, recognizes the unique echocardiographic characteristics of transcatheter devices and delivery systems, is proficient with 3D imaging, and understands the treatment goals of transcatheter valve procedures.

Although it is important that advanced imaging expertise be readily available at Comprehensive (Level I) and Primary (Level II) Valve Centers, personnel representing these imaging areas may vary between centers. Both cardiologists and cardiac anesthesiologists should have the knowledge and skills to perform and interpret procedure-based transesophageal echocardiograms, particularly if they are board certified in echocardiography. Cardiovascular imaging specialists provide advanced CT services in most institutions.

\subsubsection{Personnel, institutional facilities, and infrastruc-} ture

Complications are best managed, and outcomes optimized, by the provision of appropriate facilities and the timely availability of relevant support teams. Compliance with this basic principle requires an institutional commitment similar in scope to other interdisciplinary cardiovascular service lines such as heart transplantation and mechanical circulatory support programs. All centers should have a formal MDT composed of personnel with expertise in managing patients with VHD, including a dedicated valve program coordinator (Table 4). There should be a dedicated educational and support system that can help patients navigate the SDM process with educational aides to explain their options. Both Level I and II Valve Centers should have medical/interventional and surgical codirectors who are committed and trained to provide care to patients with VHD, as well as adequate numbers of cardiologists, interventionalists, surgeons, imagers, and anesthesiologists with expertise in cardiac valve disease. For patients presenting with heart failure due to LV systolic dysfunction and secondary MR, a heart failure specialist should be part of the MDT. Depending on the size of the program and its participation in research, advanced practice providers, nurses, and research
TABLE 4. The multidisciplinary team-minimum requirements

- Interventional cardiologist

- Cardiac surgeon

- Echocardiographic and radiographic image specialist*

- Clinical cardiology valve expertise*

- Heart failure specialist $\dagger$

- Cardiovascular anesthesiologist

- Nurse practitioner/physician assistant for pre- and periprocedural care and MDT consults

- Valve coordinator/program navigator

- Institutionally supported data manager for STS/ACC TVT Registry

- Hospital administration representative as necessary

ACC, American College of Cardiology; MDT, multidisciplinary team; STS, Society of Thoracic Surgeons; TAVR, transcatheter aortic valve repair; TVT, transcatheter valve therapy. *A single individual may provide both clinical and imaging expertise. $\dagger$ For patients with heart failure due to LV systolic dysfunction and secondary MR.

coordinators may also play an important role in the MDT and care of patients. Other members of the care team could include geriatricians, physical therapists, palliative care experts, and social workers. Additionally, Level I and II Valve Centers should have an intensive care unit (24/7 intensivist coverage for a Level I Center), cardiac anesthesia, vascular surgery, cardiac electrophysiology services for pacemaker implantation, and the ability to provide temporary mechanical support. The Comprehensive (Level I) Center should have access to emergent neurology consultations (particularly stroke services), subspecialty cardiac services (expertise in areas such as congenital heart disease, pulmonary hypertension, and advanced heart failure), and consultative medical and surgical services (eg, renal, gastrointestinal, endocrine, pulmonary, infectious disease). To facilitate alternative-access (nontransfemoral) TAVR and emerging mitral and tricuspid transcatheter therapies, a Comprehensive (Level I) Center should have a hybrid procedure room with high-quality fluoroscopic imaging, surgical-quality lighting, hemodynamic monitoring, an adequate number of display monitors, and adequate space and equipment for numerous personnel, temporary mechanical support, cardiopulmonary bypass, and rescue procedures. Access to a ventricular assist device program is required for a Comprehensive (Level I) Center, as certain high-risk procedures may result in significant ventricular dysfunction and hemodynamic deterioration. Finally, a Comprehensive (Level I) Center is required to provide a defined mechanism for timely case discussion and image sharing with Primary (Level II) Centers, general cardiologists and primary care providers.

\section{PROCESS}

\subsection{Process Requirements for Advanced Heart Valve Centers}

The process and functional requirements for Comprehensive (Level I) and Primary (Level II) Valve Centers are outlined in Table 5. 
TABLE 5. Processes for valve centers

Comprehensive (Level I) valve centers

Primary (Level II) valve centers

Documentation of formal referral and clinical pathways across the continuum of care

Documentation of communication pathways among Level I, Level II, and practice-level providers

\section{Multidisciplinary team}

All patients are evaluated by the MDT

The MDT educates patients regarding treatment recommendations, treatment options, and the use of an SDM process that incorporates patient preferences.

The MDT meets on a regular basis (preferably each week) to review cases, reach consensus management decisions, review outcomes, and assess quality.

\section{Criteria/metrics}

Documentation of attendance at MDT meetings and recording of the discussion and decision-making process for cases presented

Documentation of an action plan to address performance and quality areas needing improvement

Regular morbidity and mortality meetings

Registry participation

Participation in the STS/ACC TVT registry or other accepted national registries

Participation in the STS ACSD or other approved surgical database

\section{Criteria/metrics}

TVT registry

- $95 \%$ completion of 30-day vital status

- Of those alive, $85 \%$ completion of KCCQ at 30 days

- $90 \%$ completion of 1-year vital status

- Of those alive, $75 \%$ completion of KCCQ at 1 year

- Overall meets STS/ACC TVT Registry performance metrics for completeness and accuracy with $\geq 2$ consecutive quarters of green rating/year

National surgical database participation that meets state requirements

Surgical performance that meets STS 2- or 3-star rating criteria

Research

Participation in pivotal RCTs comparing devices or device with surgery (optional)

Publication of single-center or multicenter patient outcome studies (optional)

Education and shared decision making

Continuing education of MDT members

Education of patients and the public

Documentation of participation with patients in SDM using objective and validated resources and decision aids

Training

Structural interventional fellowship year (optional)

Cardiac surgery training in interventional structural heart skills and procedures (optional)

Advanced training in echocardiography cardiac CT and CMR for the evaluation of VHD and guidance of valve procedures (optional)

$A C C$, American College of Cardiology; $A C S D$, Adult Cardiac Surgery Database; $C M R$, cardiac magnetic resonance; $C T$, computed tomography; $K C C Q$, Kansas City Cardiomyopathy Questionnaire; $M D T$, multidisciplinary team; RCT, randomized controlled trial; STS, Society of Thoracic Surgeons; SDM, shared decision making; TVT, Transcatheter Valve Therapy; $V H D$, valvular heart disease.
The MDT educates patients regarding treatment recommendations, treatment options, and the use of an SDM process that incorporates patient preferences.

The MDT meets on a regular basis (preferably each week) to review cases, reach consensus management decisions, review outcomes, and assess quality.

Documentation of attendance at MDT meetings and recording of the discussion and decision-making process for cases presented

Documentation of an action plan to address performance and quality areas needing improvement

Regular morbidity and mortality meetings

Participation in the STS/ACC TVT registry or other accepted national registries

Participation in the STS ACSD or other approved surgical database

TVT registry

- $95 \%$ completion of 30-day vital status

- Of those alive, $85 \%$ completion of KCCQ at 30 days

- $90 \%$ completion of 1-year vital status

- Of those alive, $75 \%$ completion of KCCQ at 1 year

- Overall meets STS/ACC TVT Registry performance metrics for completeness and accuracy with $\geq 2$ consecutive quarters of green rating/year

National surgical database participation that meets state requirements

Surgical performance that meets STS 2 or 3 star rating criteria
All patients are evaluated by the MDT 


\subsection{Process Components for Advanced Heart Valve Centers}

\subsubsection{Function of the MDT}

The MDT plays a critical role in the collaborative evaluation, management, and treatment of patients with VHD. Each member of the team brings a perspective and expertise that is fundamental to optimizing patient outcomes. Although the size and specific make-up of MDT teams may differ between Comprehensive (Level I) and Primary (Level II) Valve Centers, these teams are foundational to all activities undertaken in any center.

The composition of the MDT is addressed in Section 5.2.4. and Table 4. The MDT should meet regularly (preferably each week) to review cases, verify the results of imaging and other pertinent studies, reach consensus on patient management decisions, review outcomes, and assess quality. The patient's individual needs and preferences should be discussed. Ideally, this approach leverages the combined experience and expertise of the group and leads to more standardized and evidence-based decision-making. For patients presenting with heart failure due to LV systolic dysfunction and secondary MR, a heart failure specialist is needed to ensure that optimal medical therapy has been instituted prior to consideration of interventional treatments. Other members of the MDT, such as collaborators from geriatric medicine, nephrology, and neurology, should be involved as needed. Beyond simply recommending, for example, that a patient would be best treated with SAVR or with TAVR, these MDT meetings should also provide a forum for detailed procedural planning. Input from different team members provides the best opportunity to prevent or reduce complications. The MDT is also charged with reviewing performance metrics, outcomes, quality, and external reporting. Attendance should be taken at these regular meetings, and the discussion and management decisions for each patient should be documented. An important aspect of these meetings is to support the interaction with patients in SDM using validated resources and decision aids to reach a final decision regarding therapy. ${ }^{54}$

Members of the MDT also function together during the performance of both surgical and interventional procedures. Many of the approved and emerging treatments for VHD require skillsets that extend beyond the expertise of a single individual or type of training. The norm for these procedures should be the interactive participation of multiple team members (surgeon, interventionalist, echocardiographer, and cardiac anesthesiologist, as appropriate) to reduce complications and optimize outcomes.

The MDT also analyzes and compares institutional STS/ ACC TVT Registry data against national benchmarks and develops an action plan to improve performance and outcomes if necessary. In addition, a regular mortality and morbidity conference should be held to review adverse outcomes, provide feedback in a safe environment, educate all team members, and serve as a springboard to quality improvement. Conference attendance should be documented. Continuing medical and nurse education credits should be provided, some of which can also qualify for risk management to satisfy various state licensing requirements. Data entrants are expected to participate in the ongoing activities of the STS/ACC TVT Registry and STS ACSD, to enable accurate and timely reporting. Extending MDT discussions beyond a single institution, while maintaining patient privacy and provider security, may foster more rapid dissemination of best practices.

\subsubsection{Registry participation}

Valve centers, MDTs, and professional societies need to develop and implement a scientifically rigorous approach for performance measurement and quality assessment. A commitment to programmatic quality improvement is essential. Valve centers performing TAVR must demonstrate active participation in the STS/ACC TVT Registry, with submission to the registry of all cases that use Food and Drug Administration-approved valve technology, including any off-label uses. Data reported to the STS/ ACC TVT Registry and compared against national benchmarks will facilitate maintenance of a safe, efficient, and effective valve program. This process will in turn help maintain uniformity, consistency, quality control, and a level playing field. All Comprehensive (Level I) and Primary (Level II) Valve Centers must demonstrate that data submissions meet STS/ACC TVT Registry performance metrics for completeness and accuracy, with at least 2 consecutive quarters of green rating/year. Information on QOL and survival out to 1 year will be important.

For surgical procedures, participation in either the STS ACSD or another approved national surgical registry that produces nationally benchmarked, risk-adjusted outcomes is essential. If there are requirements at the state level for participation in approved surgical registries, these should be met by all Comprehensive (Level I) and Primary (Level II) Valve Centers.

Data completeness is important for accurate reporting of outcomes and establishing national benchmarks. Both the STS Adult Cardiac Surgery Database and the STS/ACC Transcatheter Valve Therapy Registry hold participants to rigorous standards. Participants in the STS ACSD who do not meet data completeness thresholds are not included in the benchmark population for performance analysis and therefore will not be eligible to receive a composite score or participate in public reporting. Participation in a valve registry was a condition of reimbursement of the National Coverage Determination by the Center for Medicare and Medicaid Services. Extensive efforts have been used to ensure data completeness and accuracy. Completeness of any follow-up in the STS/ACC TVT registry is now $95 \%$, with $89 \%$ of records having a 30 -day follow-up completed and $68 \%$ having 1-year follow-up completed. ${ }^{55} \mathrm{~A}$ key 
outcome for the STS/ACC TVT registry is patient-reported health status, which includes a QOL metric, the Kansas City Cardiomyopathy Questionnaire (KCCQ). Currently, 90\% of baseline KCCQ scores are completed. The 30-day KCCQ score is $85 \%$ complete, with 1-year completeness being $73 \%$. It will be important that 1 -year mortality metrics and KCCQ scores be completed by all centers. It is expected that all heart valve centers will meet these 2 national registry data completeness standards.

\subsubsection{Research}

Comprehensive (Level I) and Primary (Level II) Valve Centers should be leading investigative efforts to evaluate new technologies and improve clinical management of patients with VHD. Early feasibility and first-in-man studies will be appropriate for select Comprehensive (Level I) Valve Centers. Participation in pivotal device trials will be optional for both Comprehensive (Level I) and Primary (Level II) Valve Centers provided there is an adequate research infrastructure. There remain many important clinical questions that will not be answered by industrysponsored trials but that may have a significant impact on the treatment of patients with VHD, which can be addressed by single-center or multicenter trials. Comprehensive (Level I) Valve Centers should seek to address many other questions, either by review of institutional data, analysis of existing literature, or national registry data inquiries. The role of MDT dynamics in outcomes and safety will need to be explored. Although efforts should be made to make the TVT and STS data forms as brief as possible, additional data fields could be helpful to address important research questions. Additionally, the TVT and STS registries should be leveraged to provide a framework for executing pragmatic randomized trials that would answer clinically important questions with improved efficiency, lower cost, and adequate power.

\subsubsection{Education}

Members of the Comprehensive (Level I) and Primary (Level II) Valve Centers should provide ongoing education to clinicians at local, national, and international conferences. It is also important that the centers continue to educate their own MDT members and other professionals. There should be particular emphasis on the continued education and support of the valve program coordinator, advanced practice providers, and nurses. Comprehensive (Level I) Valve Centers should interface with Primary (Level II) Valve Centers to discuss best practices, provide feedback on cases, and establish a shared understanding of when patients with VHD require referral for more complex care, as well as on-site coaching of the interventional team for technical skills. It is also important to educate patients and families to improve understanding, enable informed consent, and emphasize SDM. Further development and validation of SDM tools for patients with VHD is needed. Finally, education of the public about
VHD may help improve early detection and optimize the timing of referral. Educational strategies should be tailored to local learners, with needs assessment-based curricula, repetition, and feedback. In addition to valve centers, education regarding VHD is the responsibility of all stake holders, including device companies, imaging companies, and professional societies.

\subsubsection{Training}

Although the field continues to evolve rapidly, certain aspects have matured to the point where it is now time to implement more formalized training programs in VHD. Learning curves are to be anticipated, and procedurebased physicians who have been in practice since before the advent of transcatheter valve procedures will need to return to a structured training environment for proctoring. Such programs should include instruction on the technical and procedural aspects of intervention, as well as cognitive aspects related to patient evaluation and the timing of intervention. The Comprehensive (Level I) Centers have the responsibility to provide on-site support and education to the Primary (Level II) Centers. Expertise in VHD among cardiologists, surgeons, interventionalists, and imagers can be thought of as a subspecialty. By analogy, although heart failure can be cared for by internists and general cardiologists, advanced heart failure and transplant cardiologists are often needed to manage more complex cases requiring tiered medical and device therapies, mechanical circulatory support, or transplantation.

The rapidly changing nature of evaluation and treatment options for patients with VHD warrants specialized training and expertise. This reality has important implications for the training of cardiac surgeons, interventional cardiologists, imagers, and general cardiologists. There needs to be a new breed of VHD specialists who not only perform procedures, but also understand the underlying pathophysiology of VHD and are able to evaluate patients and determine optimal therapy. It is beyond the scope of this document to describe formal training pathways in VHD. Although not all Comprehensive (Level I) Valve Centers need to have formal fellowships in VHD, it is envisioned that most of these centers will provide such training. ${ }^{56}$

\section{PERFORMANCE METRICS}

The delivery of high-quality care requires the ability to collect data regarding the number of all treated patients and their outcomes. Collection of such data serves as the foundation for assessment of practice and procedural patterns and promotion of improvements in process and outcomes. Comparison to external benchmarks has the additional merit of maintaining uniform standards across institutions.

The proposed metrics and reporting discussed herein are relevant to both Comprehensive (Level I) and Primary 
(Level II) Valve Centers. Such reporting will initially be performed by the individual valve centers. Reporting from regionalized systems of VHD care (Figure 1), including metrics regarding communication and transitions of care, would be an aspirational goal.

\subsection{Assessment of Quality of Care and Development of Performance Metrics for VHD Centers}

The assessment of quality is fundamental to any system of VHD care. The collection of key patient-level data elements and the ability to adjust outcomes to account for the diversity of patient characteristics enable the transition from descriptive data to validated and objective performance metrics based on national benchmarks. Successfully assessing quality of care and performance for VHD centers requires a long-term and comprehensive approach to gathering the appropriate data on each patient; sharing it with an analytic center; and receiving standardized, objective, and actionable reports that include validated performance metrics benchmarked against the performance of other centers. The 2 established national registries collecting VHD-related data are focused, respectively, on surgical and transcatheter valve interventions; they represent important resources for the proposed system of VHD centers.

At the same time, there is a need to more broadly assess the quality of care in VHD patients in a way that is disease-based, comprehensive, and focused on more than simply procedures and operations. Because VHD is a chronic condition and the care of these patients extends over years, quality may be outstanding or poor at multiple time points. Timely detection of significant VHD, accurate assessment of disease severity, optimal timing of a valve procedure, and vigilant postprocedure surveillance and treatment, can all affect QOL in important ways beyond simply the technical success of the intervention. VHD has a more complex pathophysiology than just the valve; the care of VHD patients is often directed at changes in chamber size and function, thromboembolic complications, rhythm and conduction abnormalities, secondary manifestations of hepatic and renal dysfunction, and complex pulmonary and system vascular changes. These issues in comprehensively assessing quality of care are, in fact, daunting, but they need to be identified as important elements in optimizing outcomes.

The overall goals of reporting performance metrics are:

1. To provide patients and referring physicians with experience and results achieved at individual valve centers;

2. To promote the highest-quality standards for the care of patients with VHD; and

3. To establish a mechanism for every center to have a process for self-examination, and to improve continuously by using objective data that are benchmarked against national standards reported through professional society registries.

The committee recognizes that the ultimate metrics for quality standards are patient outcomes-both immediate and, ideally, long-term. However, it must be acknowledged that there are significant limitations to gathering data, performing analyses, and reporting results. Assessing in-hospital and short-term results of surgical operations and transcatheter procedures provides a beginning, but long-term outcomes, including the patient's functional status and QOL after such treatments, are key to a learning healthcare system.

There are learning curves associated with all cardiac procedures, including TAVR. ${ }^{57-59}$ Analysis of early STS/ ACC TVT Registry data shows the cumulative TAVR volume-outcome relationship is strong during the learning curve, which is expected given that this is a procedure with potentially high risk in an elderly patient population. ${ }^{60}$ In their analysis, Carroll et al. ${ }^{60}$ noted that there was a steep slope for improved major outcomes in the first 100 cases. Thus, minimum operator requirements are outlined in the 2018 AATS/ACC/SCAI/STS Expert Consensus Systems of Care Document: Operator and Institutional Requirements for Transcatheter Aortic Valve Replacement. ${ }^{26}$

The committee acknowledges that outcomes will improve with experience. Volumes alone are not necessarily the best surrogate for quality, but a volume-outcome association does exist for many cardiac procedures. ${ }^{61-67}$ Conversely, there are some procedures, such as transfemoral TAVR, that are becoming less complex and more routine with time and for which there may not be as strong a volume-outcome association. Therefore, volume recommendations must be incorporated carefully and selectively into any determination of which hospitals are designated as VHD centers. Volume thresholds are particularly challenging to determine with scientific rigor. Nevertheless, there is a need for standards because care efficiency and quality improve with the frequency of performance of major procedures and operations, just as experience leads to better results with most human endeavors. The primary motivation behind volume recommendations is not to exclude centers, but rather to serve as 1 metric in the identification of centers that are most capable of providing certain services. Patient-centered outcomes constitute the ultimate quality of care metrics and are more accurately demonstrated when volumes are sufficiently large to permit reliable statistical analysis.

The committee thus proposes that the heart valve centers be evaluated using both procedural volumes and available outcomes for each procedure. The thresholds for low-, moderate-, and high-volume centers should be based on the distribution of the number of procedures performed by 


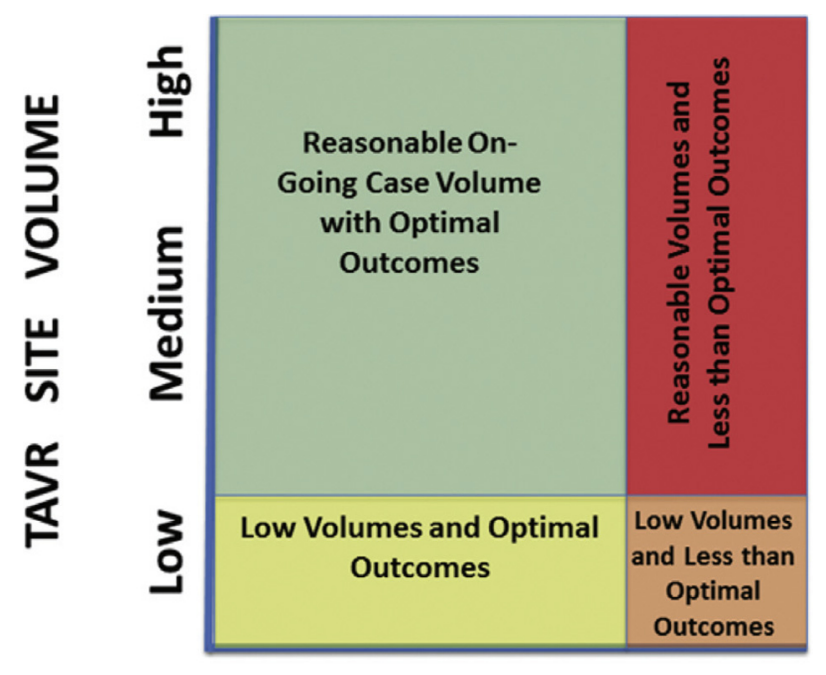

TAVR CLINICAL OUTCOMES

FIGURE 2. Categorization of sites based on tavr volume and riskadjusted mortality. This schematic categorizes TAVR programs by their case volumes and risk-adjusted clinical outcomes. Most programs have sufficient case volumes to achieve technical competence and acceptable results, although these volumes may not be sufficient to allow statistically valid quality assessments. A few programs may have adequate volumes to meet TAVR requirements and ensure statistically valid quality assessment but still appear to have suboptimal performance. These programs need to take immediate actions to improve their outcomes as it is likely they are underperforming. Some programs with lower volumes appear to have acceptable outcomes, but because of their small sample sizes, their outcome data are less statistically reliable. These programs must continue to assess their quality vigilantly. Finally, some programs have low volume and less than optimal outcomes. Although these outcomes are statistically less certain, action should be undertaken immediately to further assess and improve quality. ${ }^{35}$ TAVR, Transcatheter aortic valve replacement.

valve centers throughout the country, combined with available data on the minimum number of procedures shown to be an inflection point for outcomes.

An example of the potential relationship between volume- and risk-adjusted outcomes is shown in Figure 2. An annual threshold volume might distinguish between low-, moderate-, and high-volume centers from an experiential (but not necessarily statistical) perspective and would not exclude any center from performing the procedure. The combination of volume and risk-adjusted outcome can help to define desirable levels of performance. In Figure 2, the upper-left quadrant represents higher-volume centers with optimal risk-adjusted outcomes, most likely demonstrating higher quality. The upper-right quadrant represents highvolume centers with less than optimal risk-adjusted outcomes, for which immediate action should be taken to identify and address problems leading to higher mortality. In both instances, our confidence in estimating acceptable or substandard risk-adjusted outcomes is greater with highervolume programs because these programs' sample sizes are larger. However, it should be emphasized that the number of cases that might qualify as moderate to high volume on the basis of procedural experience is not necessarily the same as the sample size necessary to produce reliable estimates of quality, which may require accumulation of data over several years.

The lower left and right quadrant centers with lower volumes pose 2 problems: potentially inadequate volumes to achieve or maintain competence, and sample sizes that are too small to reliably estimate outcomes, as discussed in the following text. The lower-left quadrant centers should continue to assess their outcomes vigilantly, as their small sample sizes render their seemingly acceptable riskadjusted outcome estimates less statistically reliable. The lower-right quadrant centers should undertake immediate corrective actions. Although there is greater uncertainty regarding the statistical reliability of their results, their low volumes and suboptimal outcomes are worrisome.

For TAVR, serious adverse outcomes-including stroke, major bleeding, vascular complications, and mortalitywere initially shown to decrease with increasing operator experience and volume. ${ }^{60}$ As new technologies are introduced and less severely ill patients become eligible for the procedure, the threshold volumes suggested in this document may be periodically updated in response to ongoing analyses from national registries and centerspecific experiences.

The writing committee acknowledges the difficulty in correctly assessing the performance of low-volume programs. The confidence intervals around a binary event such as death increase dramatically at lower volumes, producing a graph with a "funnel on its side" appearance, with the wide end at low volumes. Because of these wide confidence intervals, the results from a low-volume program (small sample size) have substantial statistical uncertainty. It is quite difficult to ascertain from this sample what the true underlying performance is of such a program. In contrast, the narrower confidence limits inherent with moderate- and high-volume programs (large sample size) mean that estimates of their true underlying performance are more reliable, enabling their observed performance to be more confidently compared with expectations for their case mix.

To help mitigate the statistical challenges of evaluating low-volume programs, a 3-year rolling data time frame is recommended to provide more observations and better assess true differences in outcomes. Consistent with standard profiling practice, the committee recommends identifying true quality outliers as having risk-adjusted performance that is statistically significantly different than expected for their case mix on the basis of the overall performance of the benchmark population of providers for similar patients. Statistical significance is usually determined by assessing whether the $95 \%$ confidence intervals around the provider's point estimate of risk-adjusted 
mortality include the overall average mortality, or whether the confidence intervals around their ratio of observed to expected mortality include unity (ie, 1). Low-volume centers, particularly newer programs with less than 3 years of rolling data, need to be vigilant in their own internal assessments if "signals" or "trends" for poor quality are detected despite not reaching a $95 \%$ confidence level due to the challenge of accurate assessment of low-volume center quality. To provide larger sample sizes and greater statistical power, there could be a 3-year grace period for new or smaller sites to accumulate a sufficient number of cases before full accountability of outcomes is required. During the 3-year grace period, outcomes should be carefully monitored on a case-by-case basis, possibly including monitoring methods such as Cumulative Sum Control Charts and Variable Life Adjusted Display analyses, and worrisome trends in suboptimal outcomes should be addressed with action plans to enhance clinical performance. A minimum yearly volume of cases will be required to ensure programmatic efficiency and statistical relevance of outcomes.

The following section addresses the outcomes that should be reported on the basis of currently available metrics for TAVR, SAVR, and mitral valve repair. In the future, composite, multidimensional performance measures will further increase the effective number of endpoints for these procedures. This format will set the foundation for future procedures as they are evaluated and accepted into clinical practice.

\subsubsection{TAVR}

The recommended outcome measures for TAVR need to address goals of care that may differ depending on age, life expectancy, and comorbidities. These goals may include improving QOL and functional status as well as reducing rates of rehospitalization and death over a 1- to 5-year time period. TAVR is now available for intermediate-surgical-risk patients and potentially soon for low-surgical-risk patients. The goals of care for these patients overlap somewhat with those for higher-surgical-risk patients, but would also need to account for longer survival postprocedure. Clearly, there is a need to determine whether TAVR succeeds in improving functional state and QOL after hospital discharge or a 30-day time window and out to at least 1 year for all patients. These data can also be used to: (1) track the types of patients treated by the valve center; and (2) stratify outcomes according to these types.

Tables 6 and 7 include outcomes measures of quality for a TAVR program proposed in the 2018 AATS/ACC/SCAI/ STS Expert Consensus Systems of Care Document: Operator and Institutional Requirements for Transcatheter Aortic Valve Replacement. ${ }^{26}$ These proposed metrics are the beginning of an evolution in outcome assessment that can eventually approach the level of maturity, validation, and sophistication of SAVR. As outlined in Tables 6 and 7 , any valve program with an outcome metric that falls into the bottom $10 \%$ for at least 2 consecutive quarters may have a quality issue that should prompt an immediate improvement effort. A primary goal is to promote the ability of all centers to achieve both adequate volumes and acceptable outcomes (ie, the upper-left quadrant in Figure 2). It is anticipated that most low-volume sites will steadily increase their number of procedures due to the approval of moderate-risk patients for TAVR, Food and Drug Administration approval of additional indications for TAVR usage, and ongoing aging of the U.S. population.

\subsubsection{Surgical mitral valve repair}

Surgical mitral valve repair is a well-established procedure that mandates unique quality metric requirements. It has been shown that the short- and long-term results of mitral valve repair are superior to replacement in patients with severe primary MR. For patients with asymptomatic severe primary MR, surgical repair is reasonable provided a successful and durable repair rate $>95 \%$ with an operative mortality $<1 \%$ can be expected at a given center. ${ }^{1,2}$ The treatment options for asymptomatic, severe primary MR should be considered by an MDT, with repair offered only if these high standards can be met.

Data from New York State suggest that higher total annual surgeon volume is associated with increased repair rates for primary MR, with an improved 1-year survival and steady decrease in reoperation risk when $>25$ total mitral operations are performed annually. In addition, mitral valve repair rates among surgeons with volumes of $<25$ mitral operations per year increase significantly if they operate at an institution in which another surgeon performs $>50$ mitral cases per year with mitral valve repair rates for primary $\mathrm{MR}>70 \% .{ }^{17}$ Using this observational study as a single example, an appropriate cut-off for low and high surgical volumes for mitral valve operation might be $>25$ per year per operator or $>50$ per year per institution.

Current data from the Society of Thoracic Surgeons database ${ }^{68}$ indicate a repair rate well below $95 \%$ for primary degenerative disease among 867 centers in North America, reporting more than 10 such cases over a 3year period. Accordingly, on the basis of expert consensus and relevant data, it is proposed that a designated valve center should exceed that average and achieve a surgical mitral valve repair rate of greater than $75 \%$ for patients with primary degenerative MR in the absence of calcification of the leaflets or annulus (Table 8). In these patients, the 30-day operative mortality rate should be less than $1 \%$. This quality metric applies to all valve centers that are performing mitral valve operations for primary MR. To achieve this metric, it is anticipated that some centers may limit surgical mitral valve repair to those pathologies that are most easily approached (eg, isolated posterior leaflet prolapse or partial flail), whereas more experienced surgeons at a Comprehensive (Level I) Valve Center would be expected to undertake repair of more advanced 
TABLE 6. TAVR program performance minimum quality benchmarks

\begin{tabular}{ccc}
\hline & 2018 Criteria & \\
\hline Primary outcome metrics & Performance requirement \\
\hline
\end{tabular}

In-hospital risk-adjusted all-cause mortality

- Based on $95 \%$ confidence intervals and national benchmark data, the program's performance is "as expected" or "better than expected."

30-day risk-adjusted all-cause mortality

- Based on $95 \%$ confidence intervals and national benchmark data, the program's performance is "as expected" or "better than expected."

30-day all-cause neurological events, including TIAs $\dagger$

- Funnel plots using 95\% (outlier) and/or 90\% (warning) limits indicate that the program's performance falls within the selected boundaries.*

30-day major vascular complications $\dagger$

- Funnel plots using 95\% (outlier) and/or 90\% (warning) limits indicate that the program's performance falls within the selected boundaries.*

30-day major bleeding

- Funnel plots using 95\% (outlier) and/or 90\% (warning) limits indicate that the program's performance falls within the selected boundaries.*

30-day moderate or severe AR

- Funnel plots, using 95\% (outlier) and/or 90\% (warning) limits, indicate that the program's performance falls within the selected boundaries.

Primary outcome metrics in development

1-year risk adjusted all-cause mortality

Patient-reported health status (KCCQ) at 30 days and 1 year versus baseline 30-day and 1-year risk-adjusted mortality and morbidity (composite index)

$\overline{A R}$, Aortic regurgitation; KCCQ, Kansas City Cardiomyopathy Questionnaire; TIA, transient ischemic attack. *As available for reporting. $\dagger$ Presently only in-hospital and, shortly, 30-day mortality outcomes are risk adjusted. Therefore, other outcomes are not risk-adjusted and need to be interpreted in the context of a program's constellation of patients with their spectrum of characteristics that impact outcomes. Adapted from Tommaso et al. ${ }^{35}$

pathologies, as reviewed previously. In addition, each valve center may choose to limit the scope of surgical practice for individual surgeons to ensure that repair rate thresholds are met or exceeded. Many would consider mitral valve repair to constitute a surgical subspecialty ${ }^{69}$; higher individual surgeon volumes are associated with higher repair rates, decreased reoperation risk and improved survival. ${ }^{17}$ Such data support the concept of preferential referral to an expert surgeon, who would more likely operate in a Level I valve center.

\section{TABLE 7. TAVR program performance criteria}

\section{TAVR quality requirements}

To have optimal outcomes, a program will have:

- Minimum quality requirement: STS/ACC TVT Registry-reported 30-day risk-adjusted all-cause TAVR mortality above the bottom $10 \%$ for metrics outlined in Table 6.

Threshold for low- versus moderate- to high-volume centers

- $\geq 50$ cases/year or 100 cases over 2 years

\section{SAVR quality requirements}

To have optimal outcomes, a program will have:

- $\geq 2$ hospital-based cardiac surgeons who both spend $\geq 50 \%$ of their time at the hospital with the proposed TAVR program

- A quality assessment/quality improvement program:

- Active participation in the STS National Database to monitor outcomes

- Quality metric: STS 2- or 3-star rating for isolated AVR and AVR + CABG in both reporting periods during the most recent reporting year Threshold for low- versus moderate- to high-volume centers

- $\geq 30$ SAVRs/prior year or 60 SAVRs over 2 years*

$A C C$, American College of Cardiology; $A V R$, aortic valve replacement; $C A B G$, coronary artery bypass grafting; $L V A D$, left ventricular assist device; SAVR, surgical aortic valve replacement; STS, Society of Thoracic Surgeons; TAVR, transcatheter aortic valve replacement. *For the purposes of this hospital volume requirement, SAVR is defined to include all SAVR (mechanical, bioprosthesis, homograft, autograft [Ross], composite valve graft, or root replacement) or aortic valve repair procedures, including concomitant valve resuspension for acute aortic dissection and valve-sparing aortic root replacement. Simple adjuvant aortic valve procedures (eg, suturing closed regurgitant aortic valves in an LVAD patient, excising a papillary fibroelastoma or thrombus) are not included. Adapted from Tommaso et al. ${ }^{35}$ 
TABLE 8. Mitral valve repair performance criteria-for primary degenerative $M R^{*}$

To optimize outcomes, a mitral program will have:

- Repair rate $>75 \%$

- 30 -day operative mortality $<1 \%$

Threshold for moderate or high volume:

- Annual case volume of 25 per surgeon or 50 per program

$M R$, Mitral regurgitation. *In the absence of calcification of the annulus or leaflet.

\subsection{Public Reporting}

The public has a right to know the outcomes and quality achieved at a valve center. The U.S. medical system is competitive, and marketing by hospitals and healthcare systems should not be confused with a rigorous approach to high-quality, objective, comprehensive, and valid measures of performance. Public distribution of data can be misleading in the absence of data quality controls, adequate risk adjustment, and national benchmarking of each hospital's results. Public reporting of risk-adjusted outcomes is an ethical responsibility, and one that is supported by professional societies. Public reporting of a performance measure relevant to a VHD center requires a major national effort that involves multiple years of work. In the cardiac surgical field, STS has been a leader; reviewing its experience is key to considering what a system of VHD centers will need to report in addition to SAVR outcomes.

Currently, approximately $65 \%$ of cardiac surgery programs in the United States report their outcomes publicly. There is evidence that those programs that do so have better outcomes than those that do not, ${ }^{70}$ although the evidence regarding this association is variable. In addition, experience has shown that the process may have unintended consequences, such as risk aversion. ${ }^{71,72}$ The most commonly cited example of performance improvement is the New York State public reporting of cardiac surgery outcomes. $^{73-76}$ After the introduction of CABG report cards in New York State, risk-adjusted mortality declined by $41 \%$ between $1989(4.17 \%)$ and 1992 (2.45\%), with a corresponding reduction in the prevalence of high- and low-outlier hospitals. Between 1989 and 1992, New York Medicare patients experienced a $22 \%$ decline in CABG mortality rates versus a $9 \%$ decline nationwide. In 1992, New York State had the lowest Medicare CABG mortality rate in the nation. Finally, it is important that outcomes be risk-adjusted to help prevent risk avoidance and inappropriately restrictive case selection as causes of reduced mortality rates. ${ }^{73}$

STS online public reporting enables participants to voluntarily report and inform the public of their hospital's or program's heart surgery scores and star ratings. The STS began public reporting in 2010 and now publicly reports outcomes for isolated CABG, isolated AVR, and AVR plus CABG. The Society has imminent plans to report composite (risk-adjusted mortality, risk-adjusted morbidity) outcomes for mitral valve replacement, mitral valve repair, and mitral valve replacement or repair plus CABG. The publicly reported data are readily accessible through the STS website and Consumer Reports.

To make this reporting easily understandable to the public and general consumer, a 3-star rating system was constructed. This system was based on a multiprocedural, multidimensional composite measure designed to comprehensively evaluate the performance of a program or hospital on 1 of 5 common adult cardiac procedures (isolated CABG, isolated AVR, isolated mitral procedures, AVR + $\mathrm{CABG}$, and mitral procedures $+\mathrm{CABG}) .^{30,68,77-79} \mathrm{~A}$ similar composite scoring for individual surgeon performance, based on these 5 procedures, is being implemented in $2019 .{ }^{80}$ A three-star rating indicates that the provider's performance is statistically significantly better than expected for their case mix with reference to the benchmark performance of all STS programs. A 1-star rating indicates performance worse than expected for the provider's case mix.

It is expected that both Comprehensive (Level I) and Primary (Level II) Valve Centers will report outcomes of both surgery and transcatheter valve interventions (when the latter are available). In addition to risk-adjusted outcomes, transparency is needed for all stakeholders (including patients and referring physicians) regarding procedural volumes, types of patients treated, and other metrics described in this document.

\section{OBSTACLES AND CHALLENGES TO A VHD SYSTEM OF CARE}

The model proposed shares many features with other well-established systems, including integrated vertical healthcare delivery systems in which primary care is linked to tertiary/quaternary care and regional, disease-based systems, such as those championed by the National Brain Attack Coalition for acute stroke care. Both tiered and disease-based models of VHD care should help patients receive the level of care needed as a function of disease complexity. Nevertheless, there are several limitations to be recognized, including:

1. Access. The writing committee acknowledges that many patients may not be able or wish to travel to a remote center for VHD care for reasons related to age, frailty, geographic distance, separation from family, trust in their local caregivers, and the uncertainty created by placing their care in the hands of unfamiliar clinicians. There are additional barriers related to health plan coverage, restricted referral networks, lack of interoperability for both healthcare records and imaging, and perceptions of cultural bias. Many of these barriers have been addressed by large, vertically aligned healthcare 
systems in which cardiovascular specialists are employed and resources have already been consolidated to enhance efficiency. Referral out of network for other patients, however, may simply not be possible in part because of the economic environment that characterizes the current U.S. healthcare environment. In addition, some would argue that separation of patients from their local communities negates the possibility of achieving SDM. Patient preferences should always be respected, but an informed discussion of all treatment options available and the outcomes to be expected (as publicly reported), is an important prerequisite for successful SDM. Education, communication, and transparency can address some but not all of these issues. Cultural barriers to access involve more than simple geography and require interventions that are beyond the scope of this document. Whereas supporting a primary (Level II) valve center in a geographically remote/rural area is feasible on a selective basis, expanding the number of valve centers in metropolitan areas already populated by several programs is more difficult to rationalize.

2. Communication. The interoperability of electronic health records and digital imaging data needed to enable seamless patient movement within a VHD system of care is not available even within some vertically integrated health systems.

3. Cost. Comprehensive (Level I) Valve Centers will experience the higher costs associated with the management of more complex and higher-risk patients undergoing more expensive care with longer stays. Start-up and maintenance costs to establish and sustain the infrastructure required to provide comprehensive care for complex patients are substantial. Patients and families may incur higher costs related to travel or out-of-network care.

4. Professional and institutional skepticism. The writing committee also acknowledges that the simple construct of a tiered system of care may create the perception that this proposal would perpetuate the dominance of larger centers at the expense of smaller centers. The proposed concept of a system of care for VHD patients is not conceived to deny individuals and institutions the opportunity to provide services, nor should it be perceived to impede the ability of a committed center to achieve its strategic goals. Rather, it is intended to focus more on outcomes and not simply on procedural volumes, while providing a platform to guide best practices and promote quality improvement across all centers interested in the care of patients with VHD. Additionally, the proposal is not TAVR-specific but rather is meant to highlight the range of services, expertise, and experience required to care for patients across the spectrum of VHD. Health services research to assess the impact of a tiered system of care on patient outcomes, quality, and cost must be supported.

5. Knowledge and performance gaps. As discussed throughout this document, these persist despite the collective efforts of institutions, health systems, and professional societies. Enhanced collaboration and more targeted educational efforts are needed to reduce the observed variability in care and outcomes.

\section{SUMMARY AND NEXT STEPS}

The increasing burden of VHD, coupled with the emergence of improved imaging techniques, better surgical outcomes, and transcatheter therapies, has stimulated discussions regarding optimal strategies for care delivery. The focus of this document is not to ask whether there are too many, too few, or just the right number of selfdesignated advanced valve centers, but rather to initiate a discussion regarding whether a regionalized, tiered system of care for patients with VHD that accounts for the differences in valve center expertise, experience, and resources constitutes a more rational delivery model than one left to expand continuously without direction. Admittedly, access to appropriate, high-quality care remains a concern and one that is not fully addressed here, although the role of the practice-level clinician in recognition and diagnosis is acknowledged. This proposal emphasizes performance and outcome standards for all providers and centers.

There are several next steps, beginning with broad educational programming. Strategies to shorten the learning curve associated with the performance of new interventions and incorporation of iterative changes in surgical techniques deserve emphasis. Centers can share best practices for efficient MDT functioning and SDM. Communication standards, particularly at transitions of care, can be formalized. The emergence of clinical registries has enhanced centers' ability to assess and compare quality. Setting performance standards both within and across centers is thus now feasible. The Joint Commission has instituted a Comprehensive Cardiac Advanced Certification Program for individual hospitals that includes VHD care. ${ }^{81}$ External review, monitoring, and feedback at a system level, however, will be key processes going forward. These will require dedicated personnel and financing. There is a great deal of detailed work ahead to realize the goals of this proposal to the satisfaction of patients and the many other stakeholders involved.

\section{PRESIDENTS AND STAFF}

American Association for Thoracic Surgery:

David H. Adams, MD, President

Cindy VerColen, Chief Executive Officer/Executive Director

Adam Silva, Associate Director of Administration 


\section{American College of Cardiology:}

C. Michael Valentine, MD, FACC, President

Timothy W. Attebery, DSc, MBA, FACHE, Chief Executive Officer

William J. Oetgen, MD, MBA, FACC, Executive Vice President, Science, Education, Quality, and Publications

Joseph M. Allen, MA, Team Leader, Clinical Policy and Pathways

Sahisna Bhatia, MPH, Project Manager, Clinical Policy and Pathways

Amelia Scholtz, PhD, Publications Manager, Science,

Education, Quality, and Publications

American Society of Echocardiography:

Jonathan R. Lindner, MD, FASE, President

Robin Wiegerink, MNPL, Chief Executive Officer

Society for Cardiovascular Angiography and Interventions:

David A. Cox, MD, MSCAI, President

Robert Bartel, MSc, FACEHP, Vice-President, Education

\& Quality

Emily Senerth, Senior Manager, Clinical Documents \& Quality

The Society of Thoracic Surgeons:

Keith S. Naunheim, MD, President

Robert A. Wynbrandt, JD, Executive Director and General Counsel

William F. Seward, Associate Executive Director

\section{References}

1. Vahanian A, Alfieri O, Andreotti F, et al. Guidelines on the management of valvular heart disease (version 2012): The Joint Task Force on the Management of Valvular Heart Disease of the European Society of Cardiology (ESC) and the European Association for Cardio-Thoracic Surgery (EACTS). Eur Heart J. 2012;33:2451-96.

2. Nishimura RA, Otto CM, Bonow RO, et al. 2014 AHA/ACC guideline for the management of patients with valvular heart disease: a report of the American College of Cardiology/American Heart Association Task Force on Practice Guidelines. J Am Coll Cardiol. 2014;63:e57-185.

3. Nkomo VT, Gardin JM, Skelton TN, Gottdiener JS, Scott CG, EnriquezSarano M. Burden of valvular heart diseases: a population-based study. Lancet. 2006;368:1005-11.

4. d'Arcy JL, Coffey S, Loudon MA, et al. Large-scale community echocardiographic screening reveals a major burden of undiagnosed valvular heart disease in older people: the OxVALVE Population Cohort Study. Eur Heart J. 2016;37: 3515-22.

5. Carroll JD. TAVR prognosis, aging, and the second TAVR tsunami: insights from France. J Am Coll Cardiol. 2016;68:1648-50.

6. Lindroos M, Kupari M, Heikkila J, Tilvis R. Prevalence of aortic valve abnormalities in the elderly: an echocardiographic study of a random population sample. J Am Coll Cardiol. 1993;21:1220-5.

7. Durko AP, Osnabrugge RL, Van Mieghem NM, et al. Annual number of candidates for transcatheter aortic valve implantation per country: current estimates and future projections. Eur Heart J. 2018;39:2635-42.

8. Bach DS, Awais M, Gurm HS, Kohnstamm S. Failure of guideline adherence for intervention in patients with severe mitral regurgitation. J Am Coll Cardiol. 2009; $54: 860-5$.

9. Bach DS, Siao D, Girard SE, Duvernoy C, McCallister BD Jr, Gualano SK. Evaluation of patients with severe symptomatic aortic stenosis who do not undergo aortic valve replacement: the potential role of subjectively overestimated operative risk. Circ Cardiovasc Qual Outcomes. 2009:2:533-9.
10. Wang A, Grayburn P, Foster JA, et al. Practice gaps in the care of mitral valve regurgitation: Insights from the American College of Cardiology mitral regurgitation gap analysis and advisory panel. Am Heart J. 2016;172:70-9.

11. Iung B, Delgado V, Lazure $\mathrm{P}$, et al. Educational needs and application of guidelines in the management of patients with mitral regurgitation. A European mixed-methods study. Eur Heart J. 2018;39:1295-303.

12. Dziadzko V, Clavel MA, Dziadzko M, et al. Outcome and undertreatment of mitral regurgitation: a community cohort study. Lancet. 2018;391:960-9.

13. Jokinen JJ, Hippelainen MJ, Pitkanen OA, Hartikainen JE. Mitral valve replacement versus repair: propensity-adjusted survival and quality-of-life analysis. Ann Thorac Surg. 2007;84:451-8.

14. Chikwe J, Goldstone AB, Passage J, et al. A propensity score-adjusted retrospective comparison of early and mid-term results of mitral valve repair versus replacement in octogenarians. Eur Heart J. 2011;32:618-26.

15. Shuhaiber J, Anderson RJ. Meta-analysis of clinical outcomes following surgical mitral valve repair or replacement. Eur J Cardiothorac Surg. 2007;31:267-75.

16. Bolling SF, Li S, O’Brien SM, Brennan JM, Prager RL, Gammie JS. Predictors of mitral valve repair: clinical and surgeon factors. Ann Thorac Surg. 2010;90: 1904-11; discussion 1912.

17. Chikwe J, Toyoda N, Anyanwu AC, et al. Relation of mitral valve surgery volume to repair rate, durability, and survival. J Am Coll Cardiol. 2017 April 24 [E-pub ahead of print].

18. Gammie JS, O'Brien SM, Griffith BP, Ferguson TB, Peterson ED. Influence of hospital procedural volume on care process and mortality for patients undergoing elective surgery for mitral regurgitation. Circulation. 2007;115:881-7.

19. Kilic A, Shah AS, Conte JV, Baumgartner WA, Yuh DD. Operative outcomes in mitral valve surgery: combined effect of surgeon and hospital volume in a population-based analysis. J Thorac Cardiovasc Surg. 2013;146:638-46.

20. Vassileva CM, Boley T, Markwell S, Hazelrigg S. Impact of hospital annual mitral procedural volume on mitral valve repair rates and mortality. J Heart Valve Dis. 2012;21:41-7.

21. Badhwar V, Thourani VH, Ailawadi G, Mack M. Transcatheter mitral valve therapy: The event horizon. J Thorac Cardiovasc Surg. 2016;152:330-6.

22. Chatterjee S, Rankin JS, Gammie JS, et al. Isolated mitral valve surgery risk in 77,836 patients from the Society of Thoracic Surgeons database. Ann Thorac Surg. 2013;96:1587-94; discussion 1594-5.

23. Gammie JS, Sheng S, Griffith BP, et al. Trends in mitral valve surgery in the United States: results from the Society of Thoracic Surgeons Adult Cardiac Surgery Database. Ann Thorac Surg. 2009;87:1431-7; discussion 1437-9.

24. Badhwar V, Rankin JS, Thourani VH, et al. The Society of Thoracic Surgeon Adult Cardiac Surgery Database: 2018 update on research: outcomes analysis, quality improvement, and patient safety. Ann Thorac Surg. 2018;106:8-13.

25. Nishimura RA, Otto CM, Bonow RO, et al. 2017 AHA/ACC focused update of the 2014 AHA/ACC Guideline for the Management of Patients With Valvular Heart Disease: a report of the American College of Cardiology/American Heart Association Task Force on Clinical Practice Guidelines. J Am Coll Cardiol. 2017; 70:252-89.

26. Bavaria JE, Tommaso CL, Carroll J, et al. ACC/AATS/SCAI/STS expert consensus systems of care document: operator and institutional requirements for transcatheter aortic valve replacement. J Am Coll Cardiol. 2018 Jul 18 [E-pub ahead of print].

27. Alberts MJ, Latchaw RE, Selman WR, et al. Recommendations for comprehen sive stroke centers: a consensus statement from the Brain Attack Coalition. Stroke. 2005;36:1597-616.

28. Sampalis JS, Lavoie A, Boukas S, et al. Trauma center designation: initial impact on trauma-related mortality. J Trauma. 1995;39:232-7; discussion 237-9.

29. D'Agostino RS, Jacobs JP, Badhwar V, et al. The Society of Thoracic Surgeons Adult Cardiac Surgery Database: 2016 update on outcomes and quality. Ann Thorac Surg. 2016;101:24-32.

30. Shahian DM, He X, Jacobs JP, et al. The Society of Thoracic Surgeons Isolated Aortic Valve Replacement (AVR) Composite Score: a report of the STS Quality Measurement Task Force. Ann Thorac Surg. 2012;94:2166-71.

31. Nishimura RA, Otto CM, Bonow RO, et al. 2014 AHA/ACC guideline for the management of patients with valvular heart disease: a report of the American College of Cardiology/American Heart Association Task Force on Practice Guidelines. J Thorac Cardiovasc Surg. 2014;148:e1-132.

32. Otto CM, Kumbhani DJ, Alexander KP, et al. 2017 ACC expert consensus decision pathway for transcatheter aortic valve replacement in the management of adults with aortic stenosis: a report of the American College of Cardiology Task Force on Clinical Expert Consensus Documents. J Am Coll Cardiol. 2017:69:1313-46. 
33. O'Gara PT, Grayburn PA, Badhwar V, et al. 2017 ACC expert consensus decision pathway on the management of mitral regurgitation: a report of the American College of Cardiology Task Force on Expert Consensus Decision Pathways. J Am Coll Cardiol. 2017;70:2421-49.

34. Aortic Stenosis Writing G, Bonow RO, Brown AS, et al. ACC/AATS/AHA/ASE/ EACTS/HVS/SCA/SCAI/SCCT/SCMR/STS 2017 appropriate use criteria for the treatment of patients with severe aortic stenosis: a report of the American College of Cardiology Appropriate Use Criteria Task Force, American Association for Thoracic Surgery, American Heart Association, American Society of Echocardiography, European Association for Cardio-Thoracic Surgery, Heart Valve Society, Society of Cardiovascular Anesthesiologists, Society for Cardiovascular Angiography and Interventions, Society of Cardiovascular Computed Tomography, Society for Cardiovascular Magnetic Resonance, and Society of Thoracic Surgeons. J Am Soc Echocardiogr. 2018;31:117-47.

35. Bavaria JE, Tommaso CL, Brindis RG, et al. 2018 AATS/ACC/SCAI/STS expert consensus systems of care document: operator and institutional recommendations and requirements for transcatheter aortic valve replacement: a joint report of the American Association for Thoracic Surgery, the American College of Cardiology, the Society for Cardiovascular Angiography and Interventions, and the Society of Thoracic Surgeons. J Am Coll Cardiol. 2018 July 18 [E-pub ahead of print].

36. Douglas VC, Tong DC, Gillum LA, et al. Do the Brain Attack Coalition's criteria for stroke centers improve care for ischemic stroke? Neurology. 2005;64:422-7.

37. Optimal hospital resources for care of the seriously injured. Bull Am Coll Surg. 1976;61:15-22.

38. Mullins RJ, Mann NC. Population-based research assessing the effectiveness of trauma systems. J Trauma. 1999;47:S59-66.

39. Norwood S, Fernandez L, England J. The early effects of implementing American College of Surgeons level II criteria on transfer and survival rates at a rurally based community hospital. J Trauma. 1995;39:240-4; discussion 244-5.

40. Alberts MJ, Hademenos G, Latchaw RE, et al. Recommendations for the establishment of primary stroke centers. Brain Attack Coalition. JAMA. 2000;283: 3102-9.

41. Alberts MJ, Wechsler LR, Jensen ME, et al. Formation and function of acute stroke-ready hospitals within a stroke system of care recommendations from the brain attack coalition. Stroke. 2013;44:3382-93.

42. Champion JK, Pories WJ. Centers of excellence for bariatric surgery. Surg Obes Relat Dis. 2005;1:148-51.

43. O'Gara PT, Kushner FG, Ascheim DD, et al. 2013 ACCF/AHA guideline for the management of ST-elevation myocardial infarction: executive summary: a report of the American College of Cardiology Foundation/American Heart Association Task Force on Practice Guidelines. J Am Coll Cardiol. 2013;1:485-510.

44. Edwards FH, Cohen DJ, O'Brien SM, et al. Development and validation of a risk prediction model for in-hospital mortality after transcatheter aortic valve replacement. JAMA Cardiol. 2016;1:46-52.

45. Lancellotti P, Rosenhek R, Pibarot P, et al. ESC Working Group on Valvular Heart Disease position paper-heart valve clinics: organization, structure, and experiences. Eur Heart J. 2013;34:1597-606.

46. MacKenzie EJ, Rivara FP, Jurkovich GJ, et al. A national evaluation of the effect of trauma-center care on mortality. N Engl J Med. 2006;354:366-78.

47. Xian Y, Holloway RG, Chan PS, et al. Association between stroke center hospitalization for acute ischemic stroke and mortality. JAMA. 2011;305: 373-80.

48. Morton JM, Garg T, Nguyen N. Does hospital accreditation impact bariatric surgery safety? Ann Surg. 2014;260:504-8; discussion 508-9.

49. Azagury D, Morton JM. Bariatric surgery outcomes in US accredited vs nonaccredited centers: a systematic review. J Am Coll Surg. 2016;223:469-77.

50. Jollis JG, Al-Khalidi HR, Roettig ML, et al. Regional systems of care demonstration project: American Heart Association Mission: Lifeline STEMI Systems Accelerator. Circulation. 2016;134:365-74.

51. Pearlman AS, Ryan T, Picard MH, Douglas PS. Evolving trends in the use of echocardiography: a study of Medicare beneficiaries. J Am Coll Cardiol. 2007; 49:2283-91.

52. Douglas PS, Garcia MJ, Haines DE, et al. ACCF/ASE/AHA/ASNC/HFSA/HRS/ SCAI/SCCM/SCCT/SCMR 2011 Appropriate Use Criteria for Echocardiography. A Report of the American College of Cardiology Foundation Appropriate Use Criteria Task Force, American Society of Echocardiography, American Heart Association, American Society of Nuclear Cardiology, Heart Failure Society of America, Heart Rhythm Society, Society for Cardiovascular Angiography and Interventions, Society of Critical Care Medicine, Society of Cardiovascular
Computed Tomography, and Society for Cardiovascular Magnetic Resonance. J Am Coll Cardiol. 2011;57:1126-66.

53. Perk G, Kronzon I. Interventional echocardiography in structural heart disease. Curr Cardiol Rep. 2013;15:338.

54. AHRQ. The SHARE Approach. Available at: https://www.ahrq.gov/professionals/ education/curriculum-tools/shareddecisionmaking/index.html. Accessed July 30, 2018.

55. DCRI. DCRI 2017 Data Query. North Carolina Duke Clinical Research Institute, 2017.

56. Kavinsky CJ, Poulin MF, Mack MJ. Training in structural heart disease: call to action. Circulation. 2018;138:225-8.

57. Alli O, Rihal CS, Suri RM, et al. Learning curves for transfemoral transcatheter aortic valve replacement in the PARTNER-I trial: technical performance. Catheter Cardiovasc Interv. 2016;87:154-62.

58. Tommaso CL. Learning curves for TAVR: not quite see one, do one teach one. Catheter Cardiovasc Interv. 2016;87:163-4.

59. Minha S, Waksman R, Satler LP, et al. Learning curves for transfemoral transcatheter aortic valve replacement in the PARTNER-I trial: success and safety Catheter Cardiovasc Interv. 2016;87:165-75.

60. Carroll J, Vemulapalli S, Dai D, et al. The association between procedural experience for transcatheter aortic valve replacement and outcomes: insights from the STS/ACC TVT Registry. J Am Coll Cardiol. 2017.

61. Birkmeyer JD, Stukel TA, Siewers AE, Goodney PP, Wennberg DE, Lucas FL. Surgeon volume and operative mortality in the United States. N Engl J Med. 2003;349:2117-27.

62. Patel HJ, Herbert MA, Drake DH, et al. Aortic valve replacement: using a statewide cardiac surgical database identifies a procedural volume hinge point. Ann Thorac Surg. 2013;96:1560-5; discussion 1565-6.

63. Dewey TM, Herbert MA, Ryan WH, et al. Influence of surgeon volume on outcomes with aortic valve replacement. Ann Thorac Surg. 2012;93:1107-12; discussion $1112-3$

64. McNeely C, Markwell S, Filson K, Hazelrigg S, Vassileva C. Effect of hospital volume on prosthesis use and mortality in aortic valve operations in the elderly. Ann Thorac Surg. 2016;101:585-90.

65. Gonzalez AA, Dimick JB, Birkmeyer JD, Ghaferi AA. Understanding the volume-outcome effect in cardiovascular surgery: the role of failure to rescue JAMA Surgery. 2014;149:119-23.

66. Khera R, Pandey A, Koshy T, et al. Role of Hospital Volumes in Identifying LowPerforming and High-Performing Aortic and Mitral Valve Surgical Centers in the United States. JAMA Cardiol. 2017;2:1322-31.

67. Birkmeyer JD, Siewers AE, Finlayson EV, et al. Hospital volume and surgical mortality in the United States. N Engl J Med. 2002;346:1128-37.

68. Badhwar V, Rankin JS, He X, et al. The Society of Thoracic Surgeons mitral repair/replacement composite score: a report of the Society of Thoracic Surgeons Quality Measurement Task Force. Ann Thorac Surg. 2016;101: 2265-71.

69. Gillinov M, Mick S, Suri RM. The specialty of mitral valve repair. J Am Coll Cardiol. 2017 April 24 [Epub ahead of print].

70. Shahian DM, Grover FL, Prager RL, et al. The Society of Thoracic Surgeons voluntary public reporting initiative: the first 4 years. Ann Surg. 2015;262: 526-35; discussion 533-5.

71. Shahian DM, Jacobs JP, Badhwar V, D’Agostino RS, Bavaria JE, Prager RL. Risk aversion and public reporting. Part 1: observations from cardiac surgery and interventional cardiology. Ann Thorac Surg. 2017;104:2093-101.

72. Shahian DM, Jacobs JP, Badhwar V, D'Agostino RS, Bavaria JE, Prager RL. Risk aversion and public reporting. Part 2: mitigation strategies. Ann Thorac Surg. 2017; 104:2102-10.

73. Green J, Wintfeld N. Report cards on cardiac surgeons. Assessing New York State's approach. N Engl J Med. 1995;332:1229-32.

74. Hannan EL, Kumar D, Racz M, Siu AL, Chassin MR. New York State's Cardiac Surgery Reporting System: four years later. Ann Thorac Surg. 1994; 58:1852-7.

75. Hannan EL, Kilburn H Jr, Racz M, Shields E, Chassin MR. Improving the outcomes of coronary artery bypass surgery in New York State. JAMA. 1994;271: 761-6.

76. Hannan EL, Siu AL, Kumar D, Kilburn H Jr, Chassin MR. The decline in coronary artery bypass graft surgery mortality in New York State. The role of surgeon volume. JAMA. 1995;273:209-13.

77. Shahian DM, Edwards FH, Ferraris VA, et al. Quality measurement in adult cardiac surgery: part 1-conceptual framework and measure selection. Ann Thorac Surg. 2007;83:S3-12. 
78. O'Brien SM, Shahian DM, DeLong ER, et al. Quality measurement in adult cardiac surgery: part 2-statistical considerations in composite measure scoring and provider rating. Ann Thorac Surg. 2007;83:S13-26.

79. Rankin JS, Badhwar V, He X, et al. The Society of Thoracic Surgeons mitral valve repair/replacement plus coronary artery bypass grafting composite score: a report of The Society of Thoracic Surgeons Quality Measurement Task Force. Ann Thorac Surg. 2017;103:1475-81.
80. Shahian DM, He X, Jacobs JP, et al. The Society of Thoracic Surgeons composite measure of individual surgeon performance for adult cardiac surgery: a report of The Society of Thoracic Surgeons Quality Measurement Task Force. Ann Thorac Surg. 2015;100:1315-24; discussion 1324-5.

81. The Joint Commission. Comprehensive Cardiac Center Advanced Certification Program. Available at: https://www.jointcommission.org/approved_comprehen sive_cardiac_center/. Accessed March 12, 2017.

APPENDIX 1. ABBREVIATIONS

\begin{tabular}{|c|c|}
\hline $\mathrm{ACC}$ & American College of Cardiology \\
\hline AATS & American Association for Thoracic Surgery \\
\hline AS & aortic stenosis \\
\hline ASE & American Society of Echocardiography \\
\hline AVR & aortic valve replacement \\
\hline CT & computed tomography \\
\hline KCCQ & Kansas City Cardiomyopathy Questionnaire \\
\hline LV & left ventricular \\
\hline MDT & multidisciplinary team \\
\hline MR & mitral regurgitation \\
\hline SAVR & surgical aortic valve replacement \\
\hline SCAI & Society for Cardiovascular Angiography and Interventions \\
\hline SDM & shared decision making \\
\hline STEMI & ST-segment elevation myocardial infarction \\
\hline STS & Society of Thoracic Surgeons \\
\hline STS ACSD & Society of Thoracic Surgeons Adult Cardiac Surgery Database \\
\hline TAVR & transcatheter aortic valve replacement \\
\hline VHD & valvular heart disease \\
\hline
\end{tabular}




\section{APPENDIX 2. AUTHOR RELATIONSHIPS WITH INDUSTRY AND OTHER ENTITIES \\ (RELEVANT)—2018 AATS/ACC/ASE/SCAI/STS EXPERT CONSENSUS SYSTEMS OF CARE DOCUMENT: A PROPOSAL TO OPTIMIZE CARE FOR PATIENTS WITH VALVULAR HEART DISEASE}

To avoid actual, potential, or perceived conflicts of interest that may arise as a result of industry relationships or personal interests among the writing committee, all members of the writing committee, as well as peer reviewers of the document, are asked to disclose all current healthcarerelated relationships, including those existing 12 months before initiation of the writing effort. The ACC Task Force on Clinical Expert Consensus Documents reviews these disclosures to determine which companies make products (on market or in development) that pertain to the document under development. Based on this information, a writing committee is formed to include a majority of members with no relevant relationships with industry (RWI), led by a chair with no relevant RWI. RWI is reviewed on all conference calls and updated as changes occur. Author RWI pertinent to this document is disclosed in the table below and peer reviewer RWI is disclosed in Appendix 3. Additionally, to ensure complete transparency, authors' comprehensive disclosure information-including RWI not pertinent to this document-is available online. Disclosure information for the ACC Task Force on Clinical Expert Consensus Documents is also available online, as is the ACC disclosure policy for document development.

\begin{tabular}{|c|c|c|c|c|c|c|c|}
\hline $\begin{array}{c}\text { Committee } \\
\text { member }\end{array}$ & Employment & Consultant & $\begin{array}{c}\text { Speakers } \\
\text { bureau }\end{array}$ & $\begin{array}{l}\text { Ownership/ } \\
\text { partnership/ } \\
\text { principal }\end{array}$ & $\begin{array}{l}\text { Personal } \\
\text { research }\end{array}$ & $\begin{array}{l}\text { Institutional, } \\
\text { organizational, } \\
\text { or other } \\
\text { financial } \\
\text { benefit }\end{array}$ & $\begin{array}{l}\text { Expert } \\
\text { witness }\end{array}$ \\
\hline $\begin{array}{l}\text { Rick A. } \\
\text { Nishimura } \\
\text { (Co-Chair) }\end{array}$ & $\begin{array}{l}\text { Mayo Clinic, Division of } \\
\text { Cardiovascular } \\
\text { Disease-Judd and Mary } \\
\text { Morris Leighton } \\
\text { Professor of Medicine }\end{array}$ & None & None & None & None & None & None \\
\hline $\begin{array}{l}\text { Patrick T. } \\
\text { O’Gara } \\
\text { (Co-Chair) }\end{array}$ & $\begin{array}{l}\text { Harvard Medical School- } \\
\text { Professor of Medicine; } \\
\text { Brigham and Women's } \\
\text { Hospital Cardiovascular } \\
\text { Division-Director, } \\
\text { Clinical Cardiology }\end{array}$ & None & None & None & None & None & None \\
\hline $\begin{array}{l}\text { Joseph E. } \\
\text { Bavaria }\end{array}$ & $\begin{array}{l}\text { Hospital of the University } \\
\text { of Pennsylvania- } \\
\text { Director, Thoracic Aortic } \\
\text { Surgery Program }\end{array}$ & None & None & None & $\begin{array}{l}\text { - Edwards } \\
\text { Lifesciences* } \\
\text { - Medtronic* } \\
\text { - Medtronic } \\
\text { Vascular* } \\
\text { - St. Jude } \\
\text { Medical } \\
\text { - Vascutek* } \\
\text { - W.L. Gore* }\end{array}$ & $\begin{array}{l}\text { - Edwards } \\
\text { Lifesciences* } \\
\text { - Medtronic** }\end{array}$ & None \\
\hline $\begin{array}{l}\text { Ralph G. } \\
\text { Brindis }\end{array}$ & $\begin{array}{l}\text { ACC National } \\
\text { Cardiovascular } \\
\text { Data Registry-Senior } \\
\text { Medical Officer } \\
\text { Philip R. Lee Institute for } \\
\text { Health Policy Studies, } \\
\text { UCSF-Clinical } \\
\text { Professor }\end{array}$ & None & None & None & None & None & None \\
\hline
\end{tabular}




\begin{tabular}{|c|c|c|c|c|c|c|c|}
\hline $\begin{array}{l}\text { Committee } \\
\text { member }\end{array}$ & Employment & Consultant & $\begin{array}{c}\text { Speakers } \\
\text { bureau }\end{array}$ & $\begin{array}{l}\text { Ownership/ } \\
\text { partnership/ } \\
\text { principal }\end{array}$ & $\begin{array}{l}\text { Personal } \\
\text { research }\end{array}$ & $\begin{array}{l}\text { Institutional, } \\
\text { organizational, } \\
\text { or other } \\
\text { financial } \\
\text { benefit }\end{array}$ & $\begin{array}{l}\text { Expert } \\
\text { witness }\end{array}$ \\
\hline $\begin{array}{l}\text { John D. } \\
\text { Carroll }\end{array}$ & $\begin{array}{l}\text { University of Colorado } \\
\text { Denver-Professor of } \\
\text { Medicine; Director, } \\
\text { Interventional } \\
\text { Cardiology }\end{array}$ & $\begin{array}{l}\text { - St. Jude } \\
\text { Medical } \dagger\end{array}$ & None & None & $\begin{array}{l}\text { - Direct Flow* } \\
\text { - Edwards } \\
\text { Lifesciences* } \\
\text { - Evalve/Abbott } \\
\text { Structural Heart* } \\
\text { - Medtronic* } \\
\text { - St. Jude Medical } † \\
\text { - Teledyne } \\
\text { (DSMB) }\end{array}$ & $\begin{array}{l}\text { - St. Jude } \\
\text { Medical }\end{array}$ & None \\
\hline $\begin{array}{l}\text { Clifford J. } \\
\text { Kavinsky }\end{array}$ & $\begin{array}{l}\text { Rush University Medical } \\
\text { Center-Professor of } \\
\text { Medicine }\end{array}$ & None & None & None & None & None & None \\
\hline $\begin{array}{l}\text { Brian R. } \\
\text { Lindman }\end{array}$ & $\begin{array}{l}\text { Vanderbilt University } \\
\text { Medical Center- } \\
\text { Associate Professor of } \\
\text { Medicine; Medical } \\
\text { Director, Structural Heart } \\
\text { and Valve Center }\end{array}$ & $\begin{array}{l}\text { Roche } \\
\text { Diagnostics } \\
\text { Medtronic }\end{array}$ & None & None & $\begin{array}{l}\text { - Edwards } \\
\text { Lifesciences } \dagger \\
\text { - Roche } \\
\text { Diagnostics } \dagger\end{array}$ & None & None \\
\hline $\begin{array}{l}\text { Jane A. } \\
\text { Linderbaum }\end{array}$ & $\begin{array}{l}\text { Mayo Clinic-Assistant } \\
\text { Professor of Medicine; } \\
\text { Associate Medical Editor } \\
\text { for AskMayoExpert }\end{array}$ & None & None & None & None & None & None \\
\hline $\begin{array}{l}\text { Stephen H. } \\
\text { Little }\end{array}$ & $\begin{array}{l}\text { Houston Methodist } \\
\text { Hospital—Associate } \\
\text { Professor; John S. Dunn } \\
\text { Chair in Clinical } \\
\text { Cardiovascular Research } \\
\text { and Education }\end{array}$ & None & None & None & $\begin{array}{l}\text { - Abbott } \\
\text { Laboratories* } \\
\text { - Medtronic* }\end{array}$ & None & None \\
\hline $\begin{array}{l}\text { Michael J. } \\
\text { Mack }\end{array}$ & $\begin{array}{l}\text { Baylor Scott \& White } \\
\text { Health-Chair } \\
\text { Cardiovascular } \\
\text { Service Line }\end{array}$ & None & None & None & $\begin{array}{l}\text { - Abbott } \\
\text { Vascular* } \\
\text { - Edwards } \\
\text { Lifesciences* } \\
\text { - Medtronic* }\end{array}$ & None & None \\
\hline $\begin{array}{l}\text { Laura } \\
\text { Mauri }\end{array}$ & $\begin{array}{l}\text { Harvard Medical } \\
\text { School—Professor } \\
\text { of Medicine; Brigham } \\
\text { and Women's Hospital } \\
\text { Cardiovascular Division. } \\
\text { Medtronic_Global VP of } \\
\text { Clinical Research and } \\
\text { Analytics }\end{array}$ & $\begin{array}{l}\text { - } \text { Biotronik } \dagger \\
\text { - } \text { Corvia } \dagger \\
\text { - St. Jude } \\
\text { Medical } \dagger\end{array}$ & None & None & $\begin{array}{l}\text { - Abbott } \\
\text { Vascular } \dagger \\
\text { - Biotronik } \dagger \\
\text { - Boston } \\
\text { Scientific } \dagger \\
\text { - }{ }^{\dagger} \text { Corvia } \dagger\end{array}$ & None & None \\
\hline $\begin{array}{l}\text { William R. } \\
\text { Miranda }\end{array}$ & $\begin{array}{l}\text { Mayo Clinic_Cardiology } \\
\text { Fellow, Instructor in } \\
\text { Medicine }\end{array}$ & None & None & None & None & None & None \\
\hline $\begin{array}{l}\text { David M. } \\
\text { Shahian }\end{array}$ & $\begin{array}{l}\text { Massachusetts General } \\
\text { Hospital-VP } \\
\text { Quality and Safety; }\end{array}$ & None & None & None & None & None & None \\
\hline
\end{tabular}




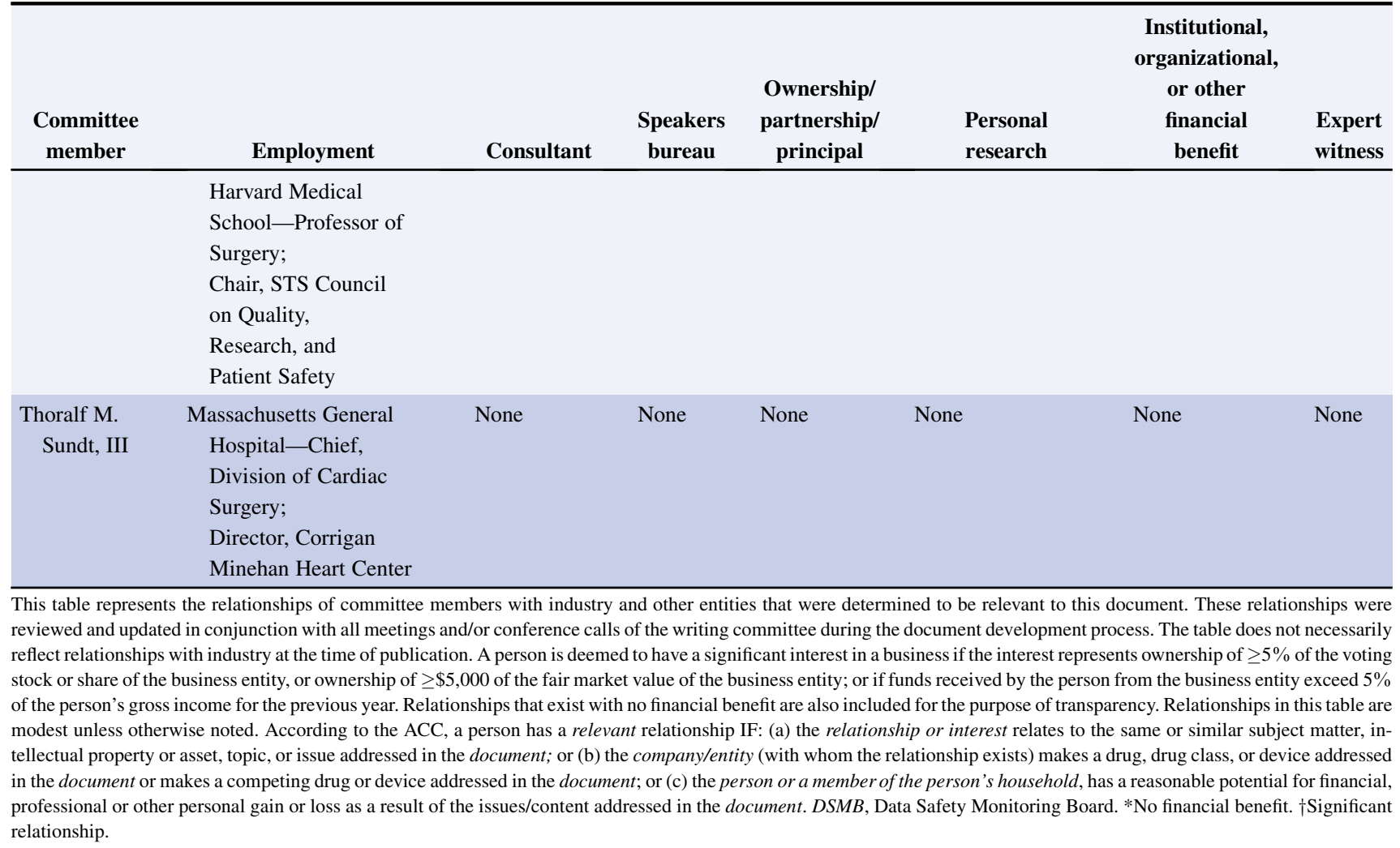


APPENDIX 3. PEER REVIEWER

INFORMATION-2018 AATS/ACC/ASE/SCAI/STS

EXPERT CONSENSUS SYSTEMS OF CARE

DOCUMENT: A PROPOSAL TO OPTIMIZE CARE

FOR PATIENTS WITH VALVULAR HEART

DISEASE
This table represents the individuals, organizations, and groups that peer reviewed this document. A list of corresponding comprehensive healthcare-related disclosures for each reviewer is available online.

\begin{tabular}{|c|c|c|}
\hline Reviewer & Representation & Employment \\
\hline Frank V. Aguirre & Official Reviewer-BOG & Prairie Cardiovascular Consultants_-Interventional Cardiologist \\
\hline Joanna Chikwe & Official Reviewer-AATS & $\begin{array}{l}\text { The Icahn School of Medicine at Mount Sinai-Professor and } \\
\text { Chief, Division of Cardiothoracic; Professor of Cardiovascular } \\
\text { Surgery; Heart Institute, Stony Brook University Medical } \\
\text { Center-Surgery Director }\end{array}$ \\
\hline Larry S. Dean & Official Reviewer-SCAI & $\begin{array}{l}\text { University of Washington School of Medicine-Professor of } \\
\text { Medicine and Surgery; UW Medicine Regional Heart Center- } \\
\text { Director }\end{array}$ \\
\hline Joseph A. Dearani & Official Reviewer-STS & Mayo Clinic_-Chair, Cardiovascular Surgery \\
\hline Daniel Engelman & Official Reviewer-AATS & $\begin{array}{l}\text { Heart, Vascular \& Critical Care Services Baystate Medical } \\
\text { Center-Interim Chief, Division of Cardiac Surgery; Medical } \\
\text { Director; University of Massachusetts Medical School- } \\
\text { Baystate-Associate Professor of Surgery }\end{array}$ \\
\hline Judy W. Hung & Official Reviewer-ASE & $\begin{array}{l}\text { Massachusetts General Hospital Cardiac-Associate Director, } \\
\text { Echocardiography, Division of Cardiology }\end{array}$ \\
\hline Chad Kliger & Official Reviewer-SCAI & $\begin{array}{l}\text { Lenox Hill Hospital—Director, Structural Heart Disease, } \\
\text { Cardiovascular Medicine; Hofstra/Northwell—Assistant } \\
\text { Professor, Donald and Barbara Zucker School of Medicine }\end{array}$ \\
\hline Leonard Y. Lee & Official Reviewer-AATS & Rutgers Robert Wood Johnson Medical School_Chairman \\
\hline Thomas E. MacGillivray & Official Reviewer-STS & $\begin{array}{l}\text { DeBakey Heart \& Vascular Center-Chief, Division of Cardiac } \\
\text { Surgery \& Thoracic Transplant Surgery }\end{array}$ \\
\hline Sunil V. Mankad & Official Reviewer-ASE & Mayo Clinic_-Associate Professor of Medicine \\
\hline James K. Min & $\begin{array}{l}\text { Official Reviewer-Task Force on Expert } \\
\text { Consensus Decision Pathways }\end{array}$ & $\begin{array}{l}\text { Dalio Institute of Cardiovascular Imaging at New York Presbyterian } \\
\text { Hospital—Professor of Radiology and Medicine; Director }\end{array}$ \\
\hline Sandra V. Abramson & Organizational Reviewer-ACP & $\begin{array}{l}\text { Lankenau Heart Pavilion—Medical Director, Cardiovascular } \\
\text { Imaging Center; Director, Interventional Echocardiography }\end{array}$ \\
\hline Oluseun O. Alli & Organizational Reviewer-Novant Health & NOVANT Heart and Vascular Institute-Assistant Professor \\
\hline Mary Beth Brady & Organizational Reviewer-SCA & $\begin{array}{l}\text { Johns Hopkins University School of Medicine-Vice Chair for } \\
\text { Education, Department of Anesthesiology and Critical Care } \\
\text { Medicine; Associate Professor, Anesthesiology and Critical Care } \\
\text { Medicine }\end{array}$ \\
\hline Samjot Brar & Organizational Reviewer-Kaiser Permanente & $\begin{array}{l}\text { Kaiser Permanente Los Angeles Medical Center and Kaiser } \\
\text { Permanente Research-Interventional Cardiologist and Vascular } \\
\text { Specialist; Chair, Regional Research Committee; The University } \\
\text { of California, Los Angeles-Assistant Clinical } \\
\text { Professor of Medicine }\end{array}$ \\
\hline Sameer A. Gafoor & Organizational Reviewer-Swedish Medical & University of Michigan Medical School—Associate Professor \\
\hline Brian B. Ghoshhajra & Organizational Reviewer-SCCT & $\begin{array}{l}\text { Massachusetts General Hospital—Service Chief, Cardiovascular } \\
\text { Imaging; Program Director, Cardiac Imaging Fellowship }\end{array}$ \\
\hline Rebecca T. Hahn & $\begin{array}{l}\text { Organizational Reviewer-Columbia University } \\
\text { College of Physicians and Surgeons }\end{array}$ & $\begin{array}{l}\text { Columbia University College of Physicians and Surgeons- } \\
\text { Associate Professor of Clinical Medicine }\end{array}$ \\
\hline
\end{tabular}


APPENDIX 3. Continued

\begin{tabular}{|c|c|c|}
\hline Reviewer & Representation & Employment \\
\hline Uzoma N. Ibebuogu & Organizational Reviewer-ABC & $\begin{array}{l}\text { University of Tennessee Health Sciences Center-Associate } \\
\text { Professor of Medicine, Division of Cardiovascular Diseases; } \\
\text { Methodist University Hospital—Director of Structural Heart } \\
\text { Disease Intervention }\end{array}$ \\
\hline Josh Rovin & Organizational Reviewer-Baycare/Morton Plant & $\begin{array}{l}\text { Morton Plant Hospital-Director, Center for Advanced Valve and } \\
\text { Structural Heart Care; Director of Transcatheter and Aortic } \\
\text { Therapies }\end{array}$ \\
\hline Scott R. Shipman & Organizational Reviewer-AAMC & $\begin{array}{l}\text { Association of American Medical Colleges-Director of Primary } \\
\text { Care Affairs and Workforce Analysis }\end{array}$ \\
\hline Amy E. Simone & Organizational Reviewer-AAPA & $\begin{array}{l}\text { Emory University Hospital Midtown—Physician Assistant, } \\
\text { Department of Cardiothoracic Surgery Structural Heart \& Valve } \\
\text { Program }\end{array}$ \\
\hline Andrew Wang & Organizational Reviewer-AHA & $\begin{array}{l}\text { Duke University Medical Center-Professor of Medicine; } \\
\text { Director, Cardiovascular Disease Fellowship Program }\end{array}$ \\
\hline Puja Banka & Content Reviewer-Imaging Council & Boston Children's Hospital—Assistant Professor of Pediatrics \\
\hline Eric R. Bates & Content Reviewer-Individual Expert & University of Michigan—Professor of Medicine \\
\hline Blasé A. Carabello & $\begin{array}{l}\text { Content Reviewer-Vascular Heart Disease } \\
\text { Guideline Writing Committee }\end{array}$ & $\begin{array}{l}\text { East Carolina Heart Institute at ECU—Professor and Chief, } \\
\text { Division of Cardiology }\end{array}$ \\
\hline Michael S. Firstenberg & Content Reviewer-Surgeons' Council & $\begin{array}{l}\text { Northeast Ohio Medical Universities—Director, Adult ECMO } \\
\text { Program; Director, Surgical Research; Associate Professor of } \\
\text { Surgery and Integrative Medicine; Summa Akron City } \\
\text { Hospital—Cardiothoracic Surgeon }\end{array}$ \\
\hline Linda D. Gillam & Content Reviewer-Health Affairs Committee & $\begin{array}{l}\text { Morristown Medical Center-Chair, Department of Cardiovascular } \\
\text { Medicine }\end{array}$ \\
\hline David R. Holmes, Jr. & Content Reviewer-ACC Roundtable Participant & $\begin{array}{l}\text { Mayo Clinic_-Professor of Medicine, Department of } \\
\text { Cardiovascular Medicine }\end{array}$ \\
\hline Alexander Iribarne & Content Reviewer-Surgeons' Council & $\begin{array}{l}\text { Dartmouth Hitchcock Medical Center-Assistant Professor of } \\
\text { Surgery }\end{array}$ \\
\hline Patricia Keegan & Content Reviewer-ACC Roundtable Participant & $\begin{array}{l}\text { Emory Structural Heart and Valve Center-Structural Heart } \\
\text { Coordinator }\end{array}$ \\
\hline Thomas M. Maddox & $\begin{array}{l}\text { Content Reviewer-Task Force on Health Policy } \\
\text { Statements and Systems of Care }\end{array}$ & $\begin{array}{l}\text { Washington University School of Medicine/BJC Healthcare- } \\
\text { Director, Health Systems Innovation Lab (HSIL); Washington } \\
\text { University School of Medicine-Professor of Medicine } \\
\text { (Cardiology) }\end{array}$ \\
\hline Elizabeth N. Perpetua & Content Reviewer-ACC Roundtable Participant & $\begin{array}{l}\text { University of Washington Medical Center-Director, Structural } \\
\text { Heart Services; Associate Director, Center for Cardiovascular } \\
\text { Emerging Therapies; Teaching Associate, Cardiology and } \\
\text { Cardiac Surgery }\end{array}$ \\
\hline Donnette Smith & Content Reviewer-ACC Roundtable Participant & Mended Hearts—President \\
\hline Carl L. Tommaso & $\begin{array}{l}\text { Content Reviewer-TAVR Requirements Writing } \\
\text { Committee Chair }\end{array}$ & $\begin{array}{l}\text { NorthShore University Health System-Associate Director, } \\
\text { Cardiac Catheterization Labs; Rush Medical College_Associate } \\
\text { Professor of Medicine }\end{array}$ \\
\hline William A. Van Decker & Content Reviewer-Health Affairs Committee & Temple University Hospital—Assistant Professor of Medicine \\
\hline Gaby Weissman & Content Reviewer-Cardiovascular Training Council & $\begin{array}{l}\text { Medstar Washington Hospital Center-Director, Cardiovascular } \\
\text { Magnetic Resonance Imaging (MRI) Core Laboratory }\end{array}$ \\
\hline Frederick G. P. Welt & Content Reviewer-Interventional Council & $\begin{array}{l}\text { University of Utah Health Sciences Center-Director, } \\
\text { Interventional Cardiology }\end{array}$ \\
\hline Michael J. Wolk & $\begin{array}{l}\text { Content Reviewer-Task Force on Health Policy } \\
\text { Statements and Systems of Care }\end{array}$ & $\begin{array}{l}\text { Weill Medical College of Cornell University_Clinical Professor of } \\
\text { Medicine }\end{array}$ \\
\hline
\end{tabular}

$\overline{A A M C}$, Association of American Medical Colleges; AATS, American Association for Thoracic Surgery; $A B C$, Association of Black Cardiologists; $A C C$, American College of Cardiology; ACP, American College of Physicians; AHA, American Heart Association; ASE, American Society of Echocardiography; ASNC, American Society of Nuclear Cardiology; SCA, Society of Cardiovascular Anesthesiologists; SCAI, Society for Cardiac Angiography and Interventions; SCCT, Society of Cardiovascular Computed Tomography; STS, Society of Thoracic Surgeons; TAVR, transcatheter aortic valve replacement. 